Research Paper

\title{
Chlorination and oxidation of the extracellular matrix protein laminin and basement membrane extracts by hypochlorous acid and myeloperoxidase
}

\author{
Tina Nybo ${ }^{\mathrm{a}}$, Simon Dieterich ${ }^{\mathrm{a}}$, Luke F. Gamon ${ }^{\mathrm{a}}$, Christine Y. Chuang ${ }^{\mathrm{a}}$, Astrid Hammer ${ }^{\mathrm{b}}$, \\ Gerald Hoefler ${ }^{\mathrm{c}}$, Ernst Malle ${ }^{\mathrm{d}}$, Adelina Rogowska-Wrzesinska ${ }^{\mathrm{e}}$, Michael J. Davies ${ }^{\mathrm{a}, *}$ \\ ${ }^{a}$ Dept. of Biomedical Sciences, University of Copenhagen, Copenhagen, Denmark \\ ${ }^{\mathrm{b}}$ Cell Biology, Histology and Embryology, Gottfried Schatz Research Center, Medical University of Graz, Graz, Austria \\ ${ }^{\mathrm{c}}$ Institute of Pathology, Diagnostic \& Research Center for Molecular BioMedicine, Medical University of Graz, Graz, Austria \\ ${ }^{\mathrm{d}}$ Molecular Biology and Biochemistry, Gottfried Schatz Research Center, Medical University of Graz, Graz, Austria \\ ${ }^{\mathrm{e}}$ Department of Biochemistry and Molecular Biology and VILLUM Center for Bioanalytical Sciences, University of Southern Denmark, Odense, Denmark
}

A R T I C L E I N F O

\section{Keywords:}

Extracellular matrix

Hypochlorous acid

Laminin

Protein oxidation

3-chlorotyrosine

Myeloperoxidase

\begin{abstract}
A B S T R A C T
Basement membranes are specialized extracellular matrices that underlie arterial wall endothelial cells, with laminin being a key structural and biologically-active component. Hypochlorous acid (HOCl), a potent oxidizing and chlorinating agent, is formed in vivo at sites of inflammation via the enzymatic action of myeloperoxidase (MPO), released by activated leukocytes. Considerable data supports a role for MPO-derived oxidants in cardiovascular disease and particularly atherosclerosis. These effects may be mediated via extracellular matrix damage to which MPO binds. Herein we detect and quantify sites of oxidation and chlorination on isolated laminin-111, and laminin in basement membrane extracts (BME), by use of mass spectrometry. Increased modification was detected with increasing oxidant exposure. Mass mapping indicated selectivity in the sites and extent of damage; Met residues were most heavily modified. Fewer modifications were detected with BME, possibly due to the shielding effects. HOCl oxidised 30 (of 56 total) Met and 7 (of 24) Trp residues, and chlorinated 33 (of 99) Tyr residues; 3 Tyr were dichlorinated. An additional 8 Met and 10 Trp oxidations, 14 chlorinations, and 18 dichlorinations were detected with the $\mathrm{MPO} / \mathrm{H}_{2} \mathrm{O}_{2} / \mathrm{Cl}^{-}$system when compared to reagent HOCl. Interestingly, chlorination was detected at $\mathrm{Tyr}_{2415}$ in the integrin-binding region; this may decrease cellular adhesion. Co-localization of MPO-damaged epitopes and laminin was detected in human atherosclerotic lesions. These data indicate that laminin is extensively modified by MPO-derived oxidants, with structural and functional changes. These modifications, and compromised cell-matrix interactions, may promote endothelial cell dysfunction, weaken the structure of atherosclerotic lesions, and enhance lesion rupture.
\end{abstract}

\section{Introduction}

The extracellular matrix (ECM) is a major component of nearly all tissues, with this providing a complex framework and 3-dimensional structure that supports associated cells and defines tissue structure. The ECM has multiple functions including: a) providing mechanical strength and elasticity; b) acting as a scaffold for cell adhesion and growth; c) controlling cell migration and proliferation; d) binding signalling molecules, pro-enzymes, enzyme inhibitors and cytokines; and e) controlling the activity of these materials [1-4]. ECM glycosaminoglycans
(GAGs, polymers of acidic or sulfated sugars) can form gels of varying pore size and charge density and thereby regulate molecular traffic. Proteoglycans (proteins with covalently-attached glycosaminoglycan chains) bind secreted signalling molecules (e.g. growth factors, cytokines) and can enhance or inhibit their activity via multiple mechanisms including: (1) immobilization thereby restricting range of action; (2) steric blocking of active sites; (3) providing a reservoir for delayed release; (4) protection from proteolytic degradation thereby prolonging action; (5) via alteration or concentration of the protein for presentation to cell-surface receptors. Alterations may therefore modulate cell

\footnotetext{
Abbreviations: 3-ClTyr, 3-chlorotyrosine; 3,5-Cl2Tyr, 3,5-dichlorotyrosine; ABTS, 2,2'-azino-bis(3-ethylbenzothiazoline-6-sulphonic acid); BME, basement mem-

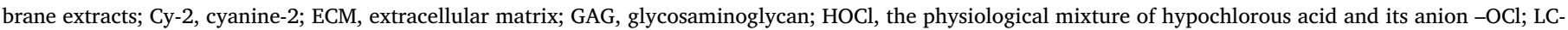

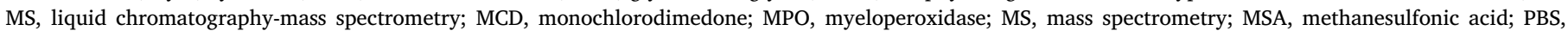
phosphate-buffered saline; RSO, relative site occupancy; SDC, sodium deoxycholate; TCA, trichloroacetic acid; TFA, trifluoroacetic acid

* Corresponding author.

E-mail address: davies@sund.ku.dk (M.J. Davies).
} 
behaviour (e.g. loss of adhesion and enhanced proliferation), and tissue structure, stability and function.

Recent studies have shown that the ECM is highly susceptible to oxidative damage due to its high abundance, its low rate of turnover (which can results in accumulation of damage during ageing and disease) and the relatively low levels of extracellular antioxidant, repairs and catabolic systems [5-7]. Considerable data has been presented that demonstrates that oxidants generated by activated leukocytes (neutrophils, monocytes, tissue macrophages) can induce structural and functional changes to ECM proteins and proteoglycans (proteins with covalently attached GAGs), with damage evident in multiple tissue samples, including within human atherosclerotic lesions [7-11].

Atherosclerosis is characterized by chronic inflammation, large numbers of activated leukocytes, lipid accumulation, endothelial cell dysfunction, smooth muscle cell migration and proliferation, loss of elasticity, calcification and in some cases lesion rupture and thrombus formation (reviewed [12,13]). Convincing data has been presented for the presence of elevated levels of oxidation products at both extra- and intra-cellular sites within plaques (e.g. [14-16]). The majority of this protein damage appears to be present on ECM materials [17].

The presence of elevated numbers of activated neutrophils and monocytes in the inflamed artery wall is known to increase plasma and tissue levels of the heme enzyme myeloperoxidase (MPO) as a result of release of this protein into the extracellular compartment or phagolysosomes, from intracellular storage granules [18-20]. MPO catalyses the formation of the potent oxidant and chlorinating agent $\mathrm{HOCl}$ from hydrogen peroxide $\left(\mathrm{H}_{2} \mathrm{O}_{2}\right)$ and chloride ions $\left(\mathrm{Cl}^{-}\right)$[21,22]. $\mathrm{HOCl}$ is important in the killing of invading pathogens, but excessive or misplaced generation can generate host tissue damage [18,23-25]. Exposure of cells to $\mathrm{HOCl}$ causes enzyme inactivation, membrane modification, dysregulated signalling, and cell death by necrosis and apoptosis $[18,19]$. Elevated MPO and HOCl levels have been implicated in multiple pathologies associated with inflammation, including cardiovascular diseases amongst others $[18,19]$.

Evidence has been presented for elevated MPO mRNA, protein and enzyme activity in human atherosclerotic lesions $[16,26]$ compared to healthy artery sections. Elevated plasma MPO levels have also been detected in subjects with established cardiovascular disease [27-30]. Biomarkers of HOCl-mediated damage are present at elevated levels in human atherosclerotic lesions, including protein-bound 3-chlorotyrosine [16,26], chlorinated nucleobases [31,32], deaminated amino acids [33], chlorinated lipids [34] and (lipo)proteins [16,35]. Strong correlations have been demonstrated between the extent of MPOmediated damage and disease severity $[16,36]$, and mice transgenic for human MPO, which have elevated levels of MPO, suffer from increased atherosclerosis [37]. Multiple epidemiological studies have shown that MPO is an independent risk factor for coronary artery disease, and a prognostic agent for determining outcomes in patients with cardiovascular disorders [27-30,38].

The basement membrane (BM) is a specialized ECM structure that underlies the endothelial cells of the artery wall, and prevents smooth muscle cell infiltration into the intimal space [4]. It is rich in laminins, type IV collagen, nidogen, entactin, perlecan amongst others $[2,4]$. These species play a critical role in determining the architecture of basement membranes, with laminins being a particularly important component, as their hetero-trimeric structure (one $\alpha$-, one $\beta$ - and one $\gamma$ chain), allows cross-links to be formed between the N-termini to form extensive laminin sheets $[3,39]$. The C-terminus of the longest $(\alpha)$ chain binds to integrins, $\alpha$-dystroglycan, heparan sulfates and sulfated glycolipids on cell surfaces, and therefore plays a critical role in cell adhesion. Binding sites for agrin and nidogen function as a link between the collagen-IV network and other ECM molecules [40]. The structure and morphology of ECM components is known to change during atherogenesis, and particularly within the fibrotic cap that stabilizes lesions and prevents plaque rupture $[12,41]$.

As MPO is released extracellularly and binds strongly to poly-anionic materials such as GAG chains [42,43], the oxidants that it generates are likely to react rapidly and to a significant extent with ECM proteins. We therefore hypothesized that both reagent $\mathrm{HOCl}$, and the $\mathrm{MPO} / \mathrm{H}_{2} \mathrm{O}_{2} / \mathrm{Cl}^{-}$system, would induce significant chemical and structural changes to laminin, and that this would modulate the chemical composition, structure and function of this protein. Previous studies have provided evidence for extensive degradation of ECM by $\mathrm{HOCl}$ and MPO-derived species [44-47], but the exact sites of damage are, in general, poorly characterized. Recently, we have reported a detailed analysis of HOCl-mediated damage to fibronectin [48]. In the current study, we have extended this approach to characterize HOCl and MPOmediated damage to isolated laminin-111 (used as model protein), and BM extracts (BME), by use of mass spectrometry (MS), as well as examining the possible presence of HOCl-derived matrix damage in human atherosclerotic lesions.

\section{Materials and methods}

\subsection{Reagents and buffers}

Murine laminin-111 was purchased from Sigma Aldrich, and murine BME (with reduced growth factors, Cultrex) was purchased from Trevigen. Laminin concentrations were calculated using a protein molecular mass of $722 \mathrm{kDa}$, based on data from Uniprot entries P19137, P02469, P02468 for the $\alpha-1, \beta-1$ and $\gamma-1$ subunits respectively. This molecular mass was also used to calculate laminin concentrations in the BME where laminin is the major component. Lysyl endopeptidase (LysC) was purchased from Wako, and trypsin from Sigma Aldrich. MPO was from Planta Natural Products. All solvents and reagents were MS grade, purchased from Sigma Aldrich, unless otherwise stated. The following antibodies were used: rat anti-mouse laminin (clone AL-2; R\& D Systems, MN, USA), mouse anti-laminin $\gamma 1$ (clone 2E8; MerckMillipore, MA, USA) and a mouse monoclonal against HOCl-modified epitopes (clone 2D10G9) [49]. Biotinylated or HRP-conjugated secondary antibodies used for ELISA and immunoblotting experiments were all from GE (IL, USA). Goat anti-mouse cyanine-2 (Cy-2)-labelled IgG was from Jackson Dianova.

\subsection{Oxidation of laminin-111 and BME}

Murine laminin-111 or murine BME were suspended in $100 \mathrm{mM}$ sodium phosphate buffer (PBS), $\mathrm{pH} 7.4$, at a concentration of $1 \mathrm{mg} \mathrm{mL}^{-1}$. Treatment with $\mathrm{HOCl}$ was carried out by bolus addition of 0,100 and $500 \mu \mathrm{M} \mathrm{HOCl}$ and incubation for $1 \mathrm{~h}$ at $21^{\circ} \mathrm{C}$. Stock concentrations of $\mathrm{HOCl}$ were quantified using a molar extinction coefficient $\left(\varepsilon_{292}\right)$ of $350 \mathrm{M}^{-1} \mathrm{~cm}^{-1}$ [50]. Enzymatic treatment was carried out at $37^{\circ} \mathrm{C}$ by addition of $0.1 \mu \mathrm{M} \mathrm{MPO}, 500 \mu \mathrm{M} \mathrm{H}_{2} \mathrm{O}_{2}$, and $100 \mathrm{mM} \mathrm{NaCl}$. Controls omitted $\mathrm{NaCl}, \mathrm{H}_{2} \mathrm{O}_{2}$, or MPO, as well as an untreated protein. $\mathrm{H}_{2} \mathrm{O}_{2}$ was added in $50 \mu \mathrm{M}$ portions at $10 \mathrm{~min}$ intervals to minimize auto-inactivation of MPO by high concentrations of $\mathrm{H}_{2} \mathrm{O}_{2}$.

\subsection{Quantification of HOCl-formation by the MPO system}

$\mathrm{HOCl}$ production by the $\mathrm{MPO} / \mathrm{H}_{2} \mathrm{O}_{2} / \mathrm{Cl}^{-}$system was quantified spectrophotometrically at $290 \mathrm{~nm}$, using the decrease in the monochlorodimedone (MCD, $1 \mathrm{M}$ stock) absorbance resulting from MCD oxidation, with a molar extinction coefficient $\varepsilon_{290}$ of $17700 \mathrm{M}^{-1} \mathrm{~cm}^{-1}$ [51].

\subsection{Protein digestion and analysis by mass spectrometry}

Laminin-111 (100 $\mu \mathrm{g})$ was digested in-solution as described 
previously [48]. Briefly, exchange of the buffer to $50 \mathrm{mM}$ triethyl ammonium bicarbonate supplemented with $4 \mathrm{M}$ urea and $1 \%$ sodium deoxycholate (SDC) was carried out for $3 \mathrm{~h}$ or overnight at $21^{\circ} \mathrm{C}$ using $10 \mathrm{kDa}$ spin-filters (Amicon Ultra-0.5 Ultracel-10K, Merck Millipore, Ireland) to remove residual reactants and salts. Digestion was performed in two steps using Lys-C ( $2 \mathrm{~h}$ in $4 \mathrm{M}$ urea), followed by trypsin (18 h in $1 \mathrm{M}$ urea) at $30^{\circ} \mathrm{C}$ to minimize protein carbamylation. SDC was subsequently removed by acidification and ethyl acetate phase transfer [52].

The resulting peptide mixture $(1 \mu \mathrm{g})$ was analysed on a QExactive HF (Thermo Fisher Scientific) using data-dependant acquisition as described previously [48]. Full scans of $m / z 400-1400$ was recorded with 120,000 resolution, and the top 12 most intense ions were selected for HCD fragmentation using a normalised collision energy (NCE) of 28. Blanks were included between each sample to monitor and prevent carry-over. Data files (.raw, Xcalibur) were analysed using Progenesis QI for proteomics (nonlinear Dynamics, USA) for chromatographic alignment and precursor peak quantification. Proteome Discoverer 2.1 was used for database searches against a murine laminin isoform database. The following search parameters were used: parent ion tolerance: $4 \mathrm{ppm}$; fragment ion tolerance: $0.1 \mathrm{Da}$; trypsin: 2 missed cleavages; fixed modifications: none; variable modifications: chlorination at Tyr (Y) and Trp (W), dichlorination at $\mathrm{Y}$ and $\mathrm{W}$, mono-oxidation at Met (M), His (H), Cys (C) and W, di-oxidation at M,C,W, and tri-oxidation at C. The peptide identifications were exported as pepXML files and imported into Progenesis QI for analysis. The resulting data were exported as comma-delimited files (.csv) providing normalised abundance calculated from the extracted ion chromatograms of precursor ions [53]. Peptide identifications were validated manually as described previously [48]. For chlorinated peptides, the isotopic distribution was inspected relative to the native peptide to confirm the characteristic enhancement of the 3rd isotopic isomer arising from the presence of chlorine isotopes [54].

\subsection{Quantification of total 3-chlorotyrosine levels by mass spectrometry} (MS)

Laminin-111 (25 $\mu \mathrm{g})$ was treated with MPO $(100 \mathrm{nM}), \mathrm{Cl}^{-}(100 \mathrm{mM})$, and varying concentrations of $\mathrm{H}_{2} \mathrm{O}_{2}$ for $2 \mathrm{~h}$ at $37^{\circ} \mathrm{C}$. The $\mathrm{H}_{2} \mathrm{O}_{2}$ was added in $50 \mu \mathrm{M}$ aliquots over $10 \mathrm{~min}$ intervals. The proteins were then processed and analysed for total 3-chlorotyrosine (3-ClTyr) as described previously [48], using 3 -chloro- $\left[{ }^{13} \mathrm{C}_{6}\right]$ tyrosine $(100 \mathrm{pmol})$ as an internal standard [55]. MS experiments which examined TCA precipitation versus spin filters versus for protein purification showed that the use of TCA did not induce artefactual chlorination (T. Nybo, M.J. Davies, A. Rogowska-Wrzesinska, unpublished data).

\subsection{Quantification of methionine oxidation and methionine sulfoxide formation by amino acid analysis}

Laminin-111 was treated with MPO-derived $\mathrm{HOCl}$, precipitated with TCA, hydrolysed with MSA, and then neutralized, as described above and previously [48]. The samples were subsequently filtered $(0.2 \mu \mathrm{m}$, Pall Nanosep filters), diluted 10-fold with MilliQ water, then $40 \mu \mathrm{L}$ transferred into vials for analysis using UPLC with pre-column derivatization using $o$-phthaldialdehyde (OPA) and fluorescence detection $[48,56]$.

\subsection{Analysis of structural changes on laminin using SDS-PAGE with silver staining and immunoblotting}

Laminin-111 samples $(0.7 \mu \mathrm{M}$ from a stock solution of $0.5 \mathrm{mg}$ protein $\mathrm{mL}^{-1}$ ) were treated with the indicated molar excesses of $\mathrm{HOCl}$ for $2 \mathrm{~h}$ at $37^{\circ} \mathrm{C}$. For gels run under reducing conditions the samples were then treated with $10 \mathrm{x}$ reducing buffer for $10 \mathrm{~min}$ at $70{ }^{\circ} \mathrm{C}$. Enzyme treated samples were generated in a similar manner to that outlined above. For 12 -well $3-8 \%$ tris acetate gels, $8 \mu \mathrm{L}$ of sample were then loaded into each well, whereas for 15-well gels $5 \mu \mathrm{L}$ of sample were loaded. The gels were developed under a constant voltage of $160 \mathrm{~V}$ for $70 \mathrm{~min}$. Bands on the gels were detected using silver staining, as described previously [9], or by immunoblotting [9] using a rat monoclonal anti-mouse laminin antibody (clone AL-2 1:20000 dilution) with detection performed using a biotinylated anti-rat secondary antibody (1:5000 dilution) and streptavidin-conjugated HRP (1:1000 dilution), developed using an ECL reagent (Perkin Elmer, MA, USA) and imaged with a chemiluminescence imager (Syngene, MD, USA).

\subsection{Detection of myeloperoxidase-derived damage by ELISA}

Laminin-111 (5 $\mu \mathrm{g} \mathrm{mL}^{-1}$ in $0.1 \mathrm{M}$ PBS, $\left.\mathrm{pH} 7.4\right)$ was coated onto clear high adhesion 96-well plates over $1 \mathrm{~h}$ at $37^{\circ} \mathrm{C}$, or overnight at $4^{\circ} \mathrm{C}$. The wells were then washed twice with $200 \mu \mathrm{L}$ PBS to remove any non-bound protein. The protein in the wells were then incubated with MPO $(20 \mathrm{nM}), \mathrm{Cl}^{-}(100 \mathrm{mM})$ and $\mathrm{H}_{2} \mathrm{O}_{2}$ (at the indicated concentrations) for $2 \mathrm{~h}$ at $37^{\circ} \mathrm{C}$. The wells were washed twice with $200 \mu \mathrm{L}$ PBS to remove residual oxidant, and then blocked with $100 \mu \mathrm{L} 0.1 \%$ casein $(\mathrm{w} / \mathrm{v})$ in PBS for $1 \mathrm{~h}$ at $21^{\circ} \mathrm{C}$. The wells were then washed twice with $200 \mu \mathrm{L}$ PBS before being incubated with 2D10G9 antibody [49] (50 $\mu \mathrm{L} ; 1: 100$ dilution) overnight at $4{ }^{\circ} \mathrm{C}$. Unbound antibody was removed $(2 \times 200 \mu \mathrm{L}$ PBS containing Tween 20$)$ and then incubated with $50 \mu \mathrm{L}$ secondary antibody (alkaline phosphatase conjugated anti-mouse IgG; $1: 1000$ dilution) in $0.1 \%$ casein (w/v) in PBS for $1 \mathrm{~h}$ at $21^{\circ} \mathrm{C}$. Any unbound secondary antibody was removed by washing $(4 \times 200 \mu \mathrm{L}$ TBST) before addition of $50 \mu \mathrm{L}$ alkaline phosphatase yellow solution. The absorbance of each well at $405 \mathrm{~nm}$ was then read every $5 \mathrm{~min}$ over a $30 \mathrm{~min}$ period using a microplate reader.

\subsection{Immunofluorescence analysis of human atherosclerotic lesions}

Tissue samples from arteriae femuralis and aortae abdominalis were obtained from 3 subjects (within $12 \mathrm{~h}$ post mortem) who died from cerebral haemorrhage. Lesions were classified according to Stary and coworkers [57] with these ranging from microscopically normal to thickened intima (lesion type II-IV). The samples were frozen in a cryostat (Microm HM500 OM; Microm, Walldorf, Germany) using tissue-freezing medium (Tissue Tec OCT-compound; Miles, Elkhard, Ind., USA). Serial cryosections ( $5 \mu \mathrm{m})$ were collected on glass slides, airdried $\left(21^{\circ} \mathrm{C}, 2 \mathrm{~h}\right)$, fixed in acetone $\left(21^{\circ} \mathrm{C}, 5 \mathrm{~min}\right)$ and stored at $-70^{\circ} \mathrm{C}$ until examined $[11,58]$. Before analysis, sections were thawed and fixed again in acetone $\left(21^{\circ} \mathrm{C}, 5 \mathrm{~min}\right)$. PBS was used to rehydrate sections, followed by blocking with Ultra $\mathrm{V}$ block for $10 \mathrm{~min}$ (Lab Vision, Fremont, CA, USA). For double immunofluorescence staining, sections were incubated first with monoclonal anti-laminin $\gamma 1$ (mouse IgG, clone 2E8; 1:100 dilution) followed by goat anti-mouse Cy-2-labelled IgG (1:300) as a secondary antibody [59]. After a blocking step with normal mouse serum (1:25) for 15 min sections were then incubated with Cy-3 labelled monoclonal antibody clone 2D10G9 (1:5) raised against HOClmodified epitopes [49]. PBS was used for washing steps and Dako antibody diluent for antibody dilutions. All incubation steps were performed at $21^{\circ} \mathrm{C}$ in dark moisture chambers. The sections were mounted with Moviol (Calbiochem-Novabiochem, La Jolla, USA), and analysed with a confocal laser-scanning microscope in sequential mode (Leica TCS SP2, Leica Lasertechnik GmbH, Heidelberg, Germany). Analysis for Cy-2 (green staining) used $\lambda_{\text {ex }} 488 \mathrm{~nm}$, and $\lambda_{\mathrm{em}} 500-540 \mathrm{~nm}$, and for Cy-3 (red staining) $\lambda_{\text {ex }} 543 \mathrm{~nm}$, and $\lambda_{\mathrm{em}} 560-620 \mathrm{~nm}$. Control experiments were performed by omission of the primary antibodies or by replacing them with non-immune mouse or rabbit IgG (Sigma-Aldrich). This study was approved by the ethics committee from the Medical 
University Graz (EK-number: 29-464 ex 16/17). All methods were performed in accordance with the relevant guidelines and regulations.

\subsection{Statistics}

For the MS data, statistical analysis was performed using Student's $t$ test using SAS Enterprise Guide 7.1 (SAS Institute Inc., USA). One-way ANOVA with post-hoc analysis using Dunnett's multiple comparison test analysis was used for UPLC and ELISA data. Data are representative of at least three independent experiments, with $\mathrm{p}<0.05$ considered significant.

\section{Results}

\subsection{HOCl induces chlorination and oxidation in murine laminin-111, and laminin chains present in $B M E$}

The effects of $\mathrm{HOCl}(100$, and $500 \mu \mathrm{M})$ and a $\mathrm{MPO} / \mathrm{H}_{2} \mathrm{O}_{2} / \mathrm{Cl}^{-}$system (with $500 \mu \mathrm{M} \mathrm{H}_{2} \mathrm{O}_{2}$ to generate the equivalent of $500 \mu \mathrm{M} \mathrm{HOCl}$; see data in [48]) on laminin-111 was studied using both purified murine protein and a BME where laminin is a major component. Sites of modification (chlorination and oxidation) were mapped and quantified by MS using a recently described method ([48]; T. Nybo et al., submitted), in which sequential Lys-C and tryptic digestion are performed without prior reduction and alkylation of the samples, as the latter have been shown to interfere with the detection and quantification of some oxidative modification ([60], T. Nybo et al., submitted). Use of this method resulted in good sequence coverage for the globular domains (LN, L4, LF, and LG) and the triple-helical long arm (I+II) of the untreated pure protein (sequence coverage excluding the LE domains: $\alpha 170.1 \%, \beta 1$ $71.3 \%, \gamma 164.0 \%$ ), but relatively poor coverage of the laminin EGF-like (LE) domains due to the high number of disulfide (cystine) cross-links in these domains (Fig. 1). A small number of peptides specific to the $\alpha 5$, $\beta 2$ and $\gamma 3$ chains were also detected in the samples (Table 1 ), together with a small number of peptides common to both $\alpha 1$ and $\alpha 5$. The presence of these peptides is likely to arise from the presence of low amounts of contaminating $\alpha 5, \beta 2$ and $\gamma 3$ laminins in the commercial preparation.

Treatment of purified laminin-111 with reagent $\mathrm{HOCl}$ (100 and $500 \mu \mathrm{M}$ ) for $1 \mathrm{~h}$ at $21^{\circ} \mathrm{C}$ and $\mathrm{pH} 7.4$, resulted in the consistent detection (in at least two out of three experimental treatments, and none of the controls) of oxidation at up to 31 Met, and 6 Trp residues, and chlorination of up to 33 Tyr residues (Table 1). Annotated MSMS spectra are given in Supplementary Fig. 1. A higher number of altered residues, and a higher extent of modification at specific sites, were detected with 500 compared to $100 \mu \mathrm{M} \mathrm{HOCl}$. A greater number of sites of modification were detected on the $\alpha 1$ chain, compared to the $\beta 1$ and $\gamma 1$ chains (Table 1). A small number of modifications were also detected on the (contaminating) $\alpha 5, \beta 2$ and $\gamma 3$ chains (Table 1 ). The higher abundance of modifications on the $\alpha 1$ chain compared to the other chains may reflect a greater number of sites accessible for modification on the longer $\alpha 1$ chain.

For the Met and Trp modifications, these were predominantly detected as $m / z+16$ species, with these assigned to Met sulfoxide, and hydroxylated products from Trp, respectively. Dioxygenation $(\mathrm{m} /$ $z+32$ species) was also detected at a limited number of Trp residues (Table 1). For the Tyr residues, these were detected as chlorinated (3ClTyr, $m / z+34 / 36$ ions) species, though 3 of these detected residues were also detected as the di-chlorinated species, $3,5-\mathrm{Cl}_{2} \mathrm{Tyr}$. In a number of cases, multiple oxidations were detected on the same peptide, consistent with either the presence of multiple readily-modified sites, or a clustering of damage. For example, the $\alpha 1$ chain peptide ${ }_{2079}$ MKDMEMQANLLLDR $_{2092}$ was detected with two or three oxygen atoms added (i.e. 2 or 3 Met sulfoxide species) at the 3 Met residues present in this sequence (Table 1 ).

Treatment of the BME samples with reagent $\mathrm{HOCl}(100$ or $500 \mu \mathrm{M})$ reproduced 21 of the Trp and Met oxidation sites, and 10 of the Tyr chlorination sites detected with purified laminin-111. In addition, one novel 3-ClTyr site, two sites with 3,5- $\mathrm{Cl}_{2}$ Tyr, two Met oxidation sites, and two Trp oxidation sites were observed. This similarity in the sites of modification suggests that a significant number of the positions in the isolated purified trimeric protein that are accessible to $\mathrm{HOCl}$, remain accessible to the oxidant in the BME. However, the overall number of sites of modification detected with the purified protein was significantly greater than with the BME, suggesting that some regions of the protein are shielded from modification by other components, or that less of the oxidant reacts with the laminin chains in the BME samples.

\subsection{The $\mathrm{MPO} / \mathrm{H}_{2} \mathrm{O}_{2} / \mathrm{Cl}^{-}$system induces chlorination and oxidation in murine laminin-111}

Analogous experiments to those outlined above were carried out using the $\mathrm{MPO} / \mathrm{H}_{2} \mathrm{O}_{2} / \mathrm{Cl}^{-}$system to determine whether the enzyme system gives rise to an altered distribution or extent of modification. The majority of chlorination and oxidation sites detected on treatment purified laminin with reagent $\mathrm{HOCl}$ were reproduced by the MPO/ $\mathrm{H}_{2} \mathrm{O}_{2} / \mathrm{Cl}^{-}$system (Table 1 ), though the enzyme system also induced modifications at a considerable number of additional sites, including 8 sites of Met oxidation, 10 sites of Trp oxidation, and 14 additional Tyr chlorination sites (Table 1). The number of sites with multiple modifications on a single residue (di-oxygenation, di-chlorination) was significantly greater with the $\mathrm{MPO} / \mathrm{H}_{2} \mathrm{O}_{2} / \mathrm{Cl}^{-}$system than with reagent

Laminin a1

\begin{tabular}{|c|c|c|c|}
\hline $\begin{array}{c}\mathrm{LN} \\
(75 \%)\end{array}$ & $\begin{array}{c}\mathrm{LEa} \\
(3 \%)\end{array}$ & $\begin{array}{c}\mathrm{LAa} \\
(59 \%)\end{array}$ & $\begin{array}{l}\text { LEb } \\
(0 \%)\end{array}$ \\
\hline
\end{tabular}

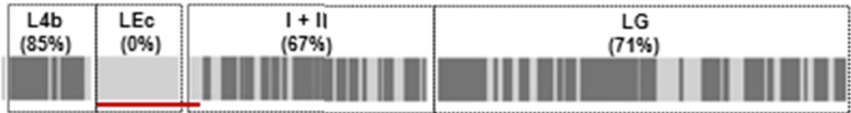

3084 aa $51 \%$
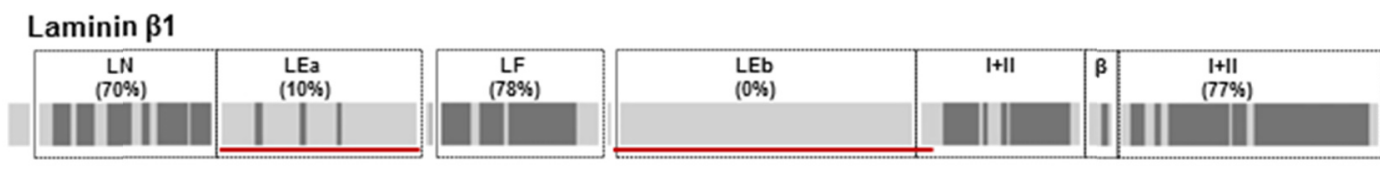

1786 aa

$46 \%$
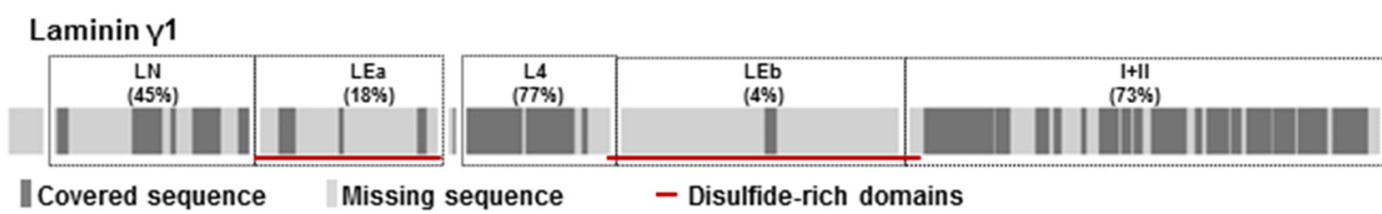

1607 aa

$45 \%$

Fig. 1. Coverage map obtained for $\alpha, \beta$, and $\gamma$-chains of murine laminin-111. Dark grey colouration indicates covered sequence, with light grey indicating missing sequence. Domain structures (LN, LE etc) are indicated by dotted line boxes; percentage values on parentheses indicate sequences coverage of each domain. Regions rich on disulfide bonds (cystines; indicated by red lines) are indicated. Overall length and \% sequence coverage for each chain are indicated at the end of each map. 
Table 1

List of sites of oxidation (at Met, Trp) and chlorination (Tyr) identified in purified murine laminin-111 (1.18 $\mu \mathrm{M})$ or laminin present in murine basement membrane extract (ECM; $1 \mu \mathrm{g}$ protein) treated with 0,100 , and $500 \mu \mathrm{M} \mathrm{HOCl}$, or a MPO $(100 \mathrm{nM}) / \mathrm{H}_{2} \mathrm{O}_{2}(500 \mu \mathrm{M}) / \mathrm{Cl}^{-}(100 \mathrm{mM})$ system in $100 \mathrm{mM} \mathrm{PBS}, \mathrm{pH} 7.4$, for $1 \mathrm{~h}$ at $21^{\circ} \mathrm{C}$. Data are presented in sequence residue order for each of the laminin chains. The modified residues are indicated together with type of modification and the detected peptide(s) (with start and stop numbering) which contain these residues, with the modified amino acid highlighted. Modifications are coded as follows: $\mathrm{Cl}=3$-chloroTyr; $\mathrm{Cl}_{2}=3,5$ dichloroTyr; 2 x Cl = two 3-chloroTyr modifications in the peptide at the indicated residues; $\mathrm{O} 1=$ mono-oxygenation; $\mathrm{O} 2=$ di-oxygenation; 2 x O, 3 x $\mathrm{O}, 4 \mathrm{x} \mathrm{O}=$ two, three or four mono-oxygenations at residues within the peptide at the indicated residues. - indicates modification detected with the stated oxidant system.

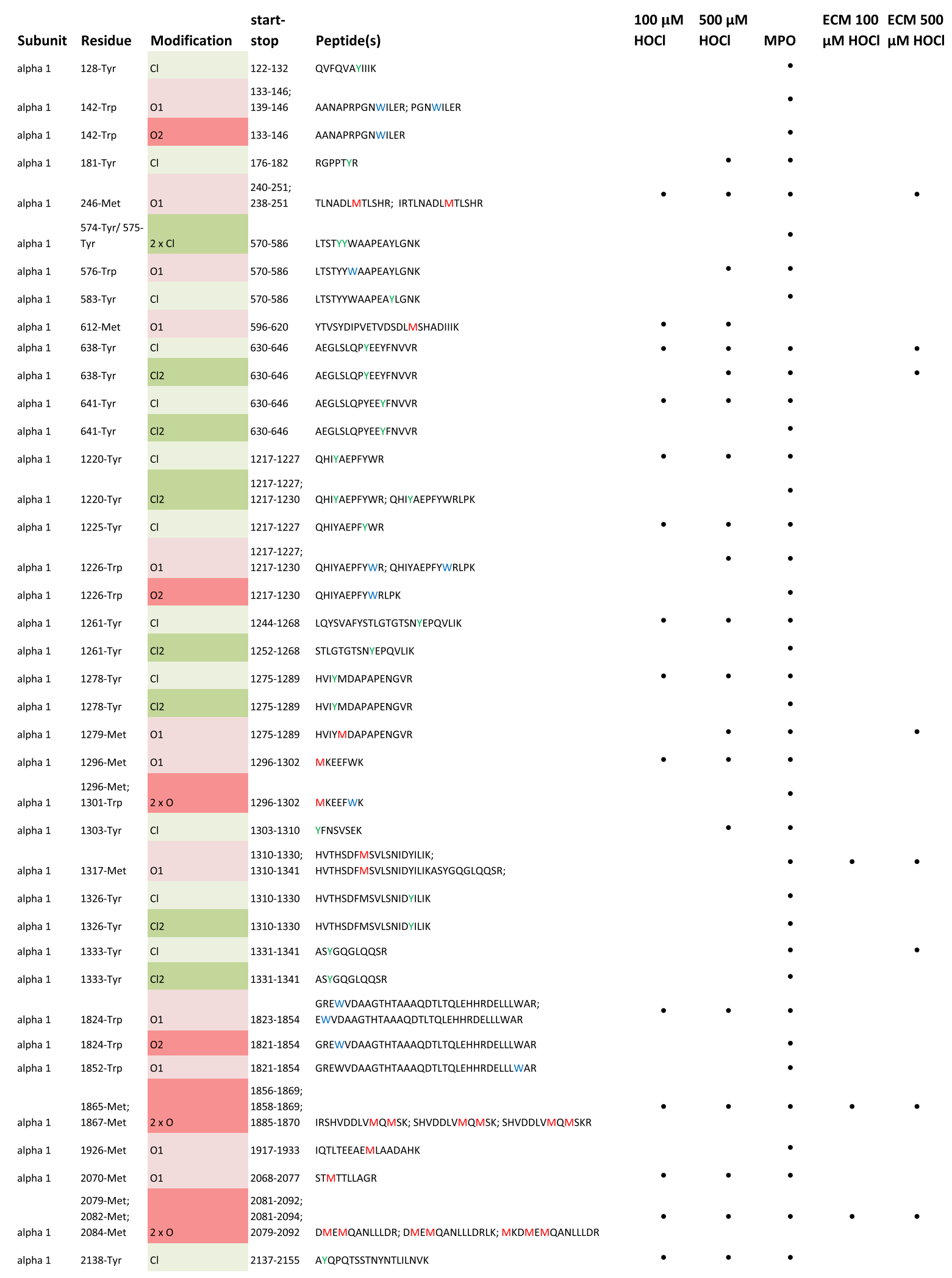


Table 1 (continued)

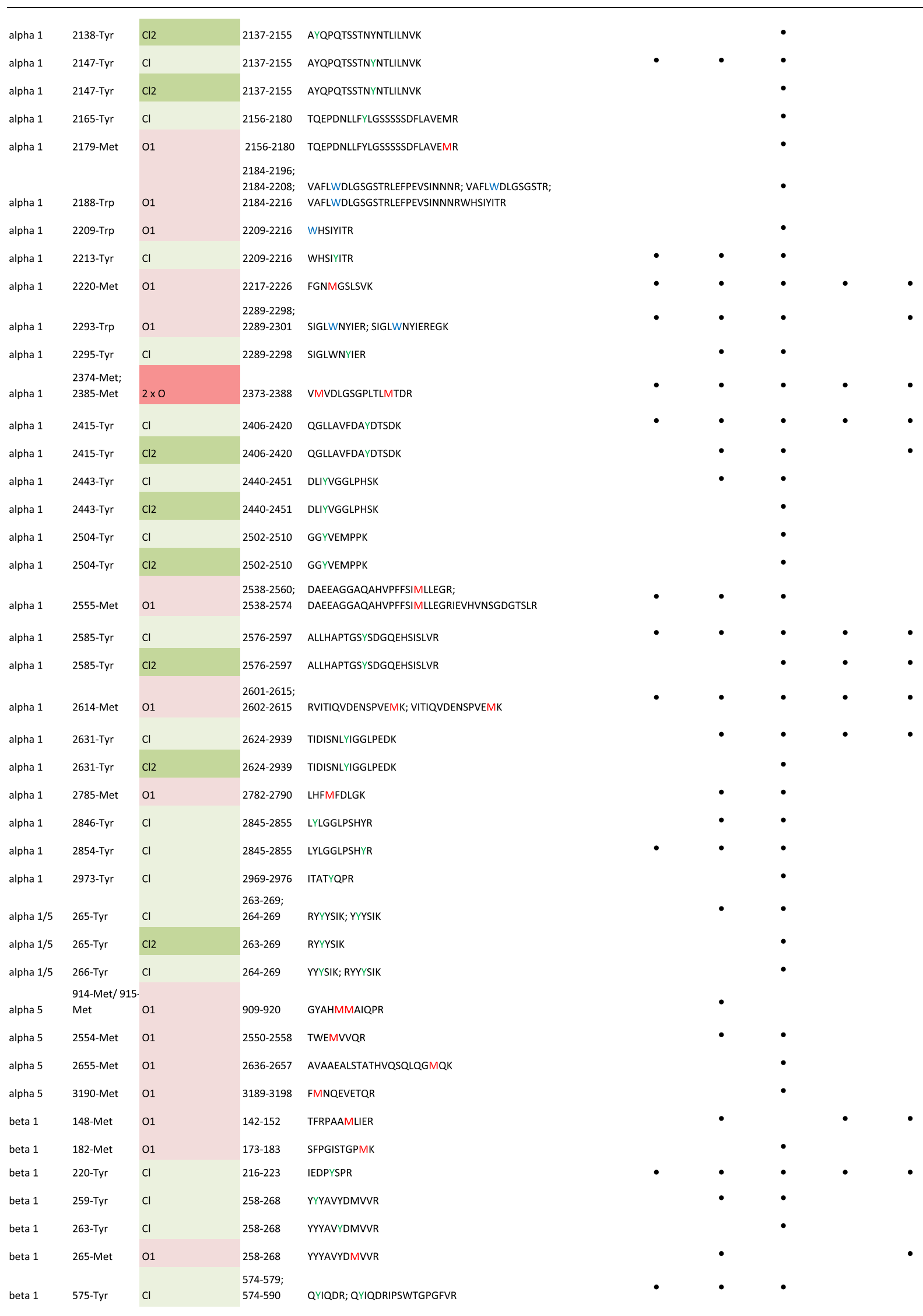


Table 1 (continued)

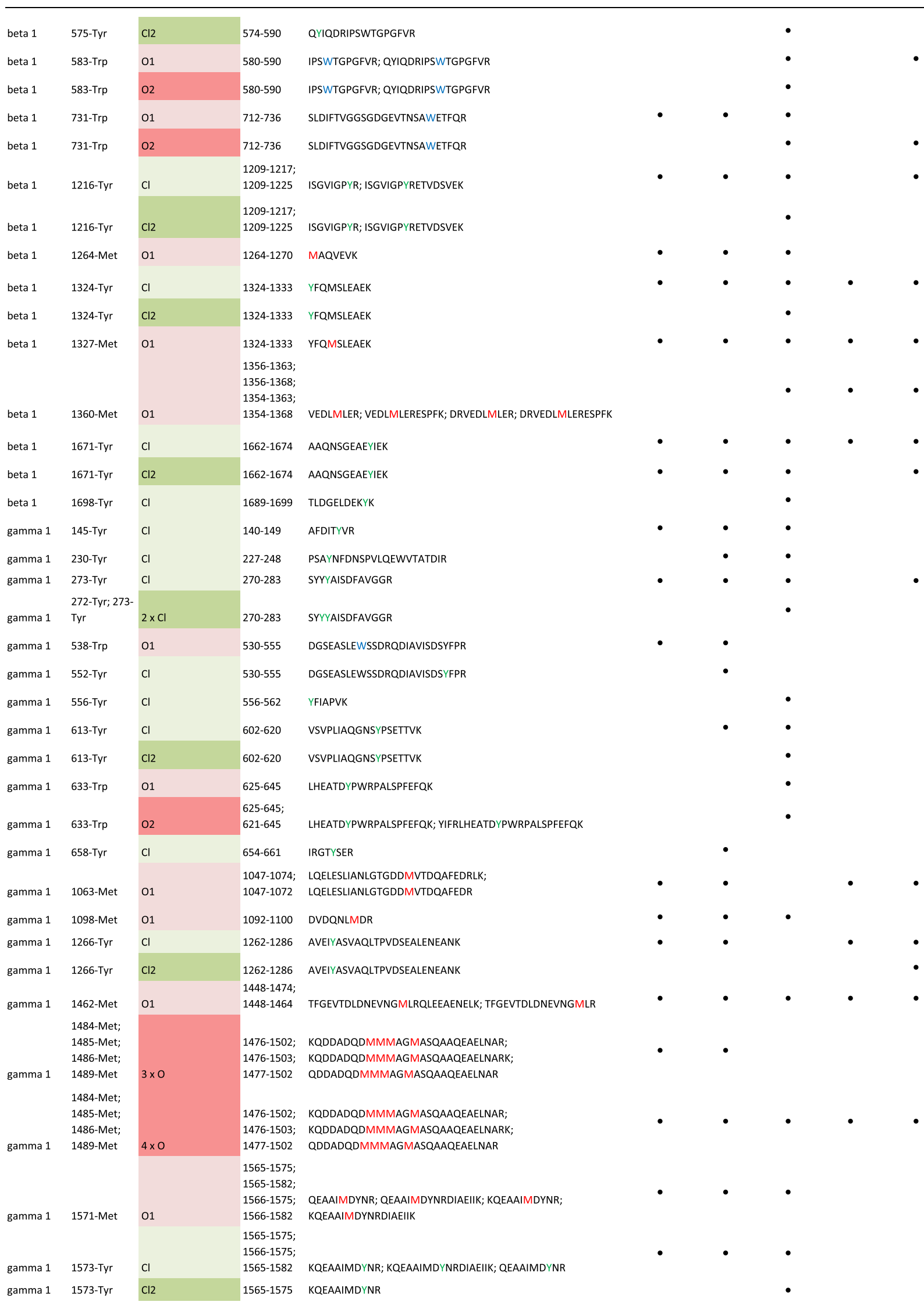


$\mathrm{HOCl}$, as were the number of modifications detected on the (contaminating) $\alpha 5, \beta 2$ and $\gamma 3$ chains (Table 1). Experiments with the $\mathrm{MPO} / \mathrm{H}_{2} \mathrm{O}_{2} / \mathrm{Cl}^{-}$system and BME were not carried out as MPO is known to bind to multiple BME components $[61,62]$, with this potentially confounding the data analysis.

\subsection{Laminin is highly susceptible to damage induced by the $\mathrm{MPO} / \mathrm{H}_{2} \mathrm{O}_{2} / \mathrm{Cl}^{-}$ system}

The extent of modification at each of the identified sites of modification on laminin was evaluated by the relative site occupancy (RSO; the $\%$ conversion of a specific site to a particular product) [63]. Fig. 2 shows the site assignment and RSO of the modifications induced by $500 \mu \mathrm{M} \mathrm{HOCl}$ and the $\mathrm{MPO} / \mathrm{H}_{2} \mathrm{O}_{2} / \mathrm{Cl}^{-}$system (with $500 \mu \mathrm{M} \mathrm{H} \mathrm{H}_{2} \mathrm{O}_{2}$, and hence $\sim 500 \mu \mathrm{M} \mathrm{HOCl}$ [48]) on purified laminin (PL:HOCl and PL: MPO respectively), and by $500 \mu \mathrm{M} \mathrm{HOCl}$ on laminin in the BME (BME:HOCl). Peptide quantification data are presented in Supplementary Tables 1-3 and Supplementary Figs. 2-7. As indicated in Fig. 2A, the MPO-system induced a markedly greater extent of modification than reagent $\mathrm{HOCl}$, particularly on the $\alpha 1$-chain. This difference was less dramatic with the $\beta 1$ and $\gamma 1$ chains, suggesting that MPO may associate with, and hence direct oxidation to particular regions on this chain.

Although fewer sites were identified on the laminin chains present in the BME than with isolated laminin (Table 1), the RSO values detected for the BME were generally comparable with those detected with the HOCl-treated purified protein. These data are consistent with the hypothesis that the composition, or the interactions between laminin and other components in the $\mathrm{BM}$, affect the regions of the protein that are exposed to the oxidant.

\subsection{Quantification of isobaric peptide forms}

A number of peptides were detected that contained more than a single site of modification with this resulting in the detection of isobaric (identical mass) species. In some cases, these species could be separated by chromatography on the basis of the altered hydrophobicity of the peptide. Thus, $\mathrm{Tyr}_{638}$ and $\mathrm{Tyr}_{641}$ were both detected as sites of modification in the peptide, ${ }_{630} \mathrm{AEGLSLQPYEEYFNVVR}_{646}$, with these residue being converted to $3-\mathrm{ClTyr}$ and $3,5-\mathrm{Cl}_{2}$ Tyr (Fig. 3). Quantitative data was obtained for both sites in this peptide, as the sequence position of the chlorination delays the chromatographic elution to a higher degree when the chlorination is present on $\mathrm{Tyr}_{641}$ compared to $\mathrm{Tyr}_{638}$. Treatment of purified laminin with reagent HOCl resulted in 3-ClTyr formation at both Tyr residues, with a greater extent of modification (RSO) at $\mathrm{Tyr}_{638}$. Thus with $500 \mu \mathrm{M} \mathrm{HOCl}$, the RSO at $\mathrm{Tyr}_{638}$ and $\mathrm{Tyr}_{641}$ were $6.5 \%$ and $2.2 \%$, respectively, with additional formation of 3,5$\mathrm{Cl}_{2}$ Tyr detected at $\mathrm{Tyr}_{638}$ with a RSO value of $0.25 \%$ (Fig. 4A). With the $\mathrm{MPO} / \mathrm{H}_{2} \mathrm{O}_{2} / \mathrm{Cl}^{-}$system, 3-ClTyr and 3,5- $\mathrm{Cl}_{2} \mathrm{Tyr}$ were detected at both sites, however in this case the extracted ion chromatograms of the mono-chloro species (3-ClTyr) were not resolved for the two sites, thus the quantification data reported reflects the sum of the contribution at the two sites (RSO 12.1\%). For the di-chlorinated species, the data were resolved with the RSO values for $3,5-\mathrm{Cl}_{2} \mathrm{Tyr}$ formation being $2.71 \%$ and $0.95 \%$ for $\operatorname{Tyr}_{638}$ and $\mathrm{Tyr}_{641}$, respectively, and hence a greater extent of reaction at $\operatorname{Tyr}_{638}$.

\subsection{Oxidation of Met residues can result in neutral loss of methane sulfenic acid $\left(\mathrm{CH}_{3} \mathrm{SOH}\right)$ that complicates quantification}

Met sulfoxide has been shown previously to undergo a neutral loss of $\mathrm{CH}_{3} \mathrm{SOH}$ [64], which may confound quantification. In the current study, the peptide ${ }_{2081}$ DMEMQANLLLDR $_{2092}$ containing two Met residues $\left(\mathrm{Met}_{2082}\right.$ and $\mathrm{Met}_{2084}$ ) was detected with multiple modifications induced by HOCl. Fig. 5 shows MS fragmentation spectra of the native peptide, together with those for peptides with single oxidations $(\mathrm{m} /$ $z+16$; sulfoxide formation) at $\mathrm{Met}_{2082}$ and $\mathrm{Met}_{2084}$, respectively. The +16 Da mass shifts consistent with the addition of a single oxygen atom, are marked (dotted grey lines) for the diagnostic ions, $\mathrm{y}_{9}$ for $\mathrm{Met}_{2084}$ and $\mathrm{b}_{2}$ for $\mathrm{Met}_{2082}$. The ions $\mathrm{y}_{9}$ and $\mathrm{y}_{10}$ contain only Met $\mathrm{Mes4}_{20}$, and in the oxidised form, neutral loss of $\mathrm{CH}_{3} \mathrm{SOH}$ was observed for both ions (Fig. 5C). Similarly, the $\mathrm{b}_{2}$ and $\mathrm{b}_{3}$ ions containing Met $_{2082}$ show $\mathrm{CH}_{3} \mathrm{SOH}$ loss when the modification is present at this site (Fig. 5B).

The concentration dependence of the changes in RSO values for some of the modifications provides information on the susceptibility of different residues to modification. Fig. 6A indicates the dose dependence of oxidation of the $\mathrm{Met}_{2082}$ and $\mathrm{Met}_{2084}$ residues. The latter shows a high susceptibility to oxidation under control conditions with a background RSO of $\sim 55 \%$ compared to $\sim 2 \%$ for Met $_{2082}$. With $100 \mu \mathrm{M} \mathrm{HOCl}$, the parent peptide is nearly $100 \%$ depleted, and $\mathrm{Met}_{2084}$ shows a RSO of $\sim 100 \%$. With $500 \mu \mathrm{M} \mathrm{HOCl}, \mathrm{Met}_{2084}$ is fully oxidised and the extent of Met $_{2082}$ oxidation is increased to $47 \%$, indicating that oxidation occurs at $\mathrm{Met}_{2084}$ in preference to $\mathrm{Met}_{2082}$. Somewhat different behaviour is seen with the peptide ${ }_{1476} \mathrm{KQDDADQDMMMAGM}$ ASQAAQEAELNAR $_{1502}$ which appears to be an oxidation 'hotspot' with modification $(m / z+16$; sulfoxide formation) detected at all 4 Met residues in this sequence (Fig. 6B). Under control conditions, the native peptide has a total RSO value (for mono-oxidation at one of the 4 Met residues) of $\sim 49 \%$, and $\sim 36 \%$ for di-oxidation (two sulfoxides). After exposure to $100 \mu \mathrm{M} \mathrm{HOCl}$, the parent and singly oxidised peptide forms are depleted (Fig. 6B), with species containing three Met oxidations being the dominant form (RSO 51\%). With $500 \mu \mathrm{M}$ HOCl, this sequences has a RSO for tetra-oxidation (i.e. sulfoxide formation at all 4 Met residues) of $\sim 88 \%$, with tri-oxidation accounting for $\sim 11 \%$. However, unlike the situation with the peptide ${ }_{2081}$ DMEMQANLL$\mathrm{LDR}_{2092}$ discussed above, the four Met residues in this peptide appear to be oxidised in a random order, with no detectable preference for oxidation at particular Met residues.

\subsection{Quantification of total methionine and methionine sulfoxide levels by amino acid analysis}

In order to determine the total extent of Met modification, Met sulfoxide formation, and whether further products were formed (cf. the data above for extensive Met oxidation), amino acid analysis for carried out for the complete protein exposed to the MPO/ $\mathrm{H}_{2} \mathrm{O}_{2} / \mathrm{Cl}^{-}$system (using $500 \mu \mathrm{M} \mathrm{H}_{2} \mathrm{O}_{2}$ ). Experiments were only carried out with this system due to the amount of purified protein required, and its greater biological relevance. The data obtained (Fig. 7A,B) confirm that MPO/ $\mathrm{H}_{2} \mathrm{O}_{2} / \mathrm{Cl}^{-}$depletes parent Met, and enhances Met sulfoxide formation, with the extent of Met depletion ( 11 pmoles lost) showing a high percentage conversion $(\sim 73 \%)$ to the sulfoxide $(\sim 8$ pmole increase). These data confirm that Met sulfoxide is the major product formed from Met residues in the complete protein sequence, and that this pathway consumes a considerable proportion of the HOCl generated $(\sim 15 \%$ based on the total Met and Met sulfoxide detected by this method). No evidence was obtained for Met sulfone formation, but low levels of this di-oxygenated species, or other products (cf. data in [65]) cannot be excluded. The formation of other materials may account for the (small) discrepancy between the quantity of Met lost and sulfoxide formed.

\subsection{Quantification of total 3-ClTyr levels by amino acid analysis}

Using a similar approach to that outlined above for Met oxidation, total 3-ClTyr yields on the protein were determined by LC-MS analysis for the $\mathrm{MPO} / \mathrm{H}_{2} \mathrm{O}_{2} / \mathrm{Cl}^{-}$system. The data obtained (Fig. $7 \mathrm{C}$ ) indicate (as expected) that very low levels of 3-ClTyr were present in the control samples, and that these are markedly elevated on treatment with the $\mathrm{MPO} / \mathrm{H}_{2} \mathrm{O}_{2} / \mathrm{Cl}^{-}$system (using $500 \mu \mathrm{M} \mathrm{H}_{2} \mathrm{O}_{2}$ ). Quantification of the 3- 

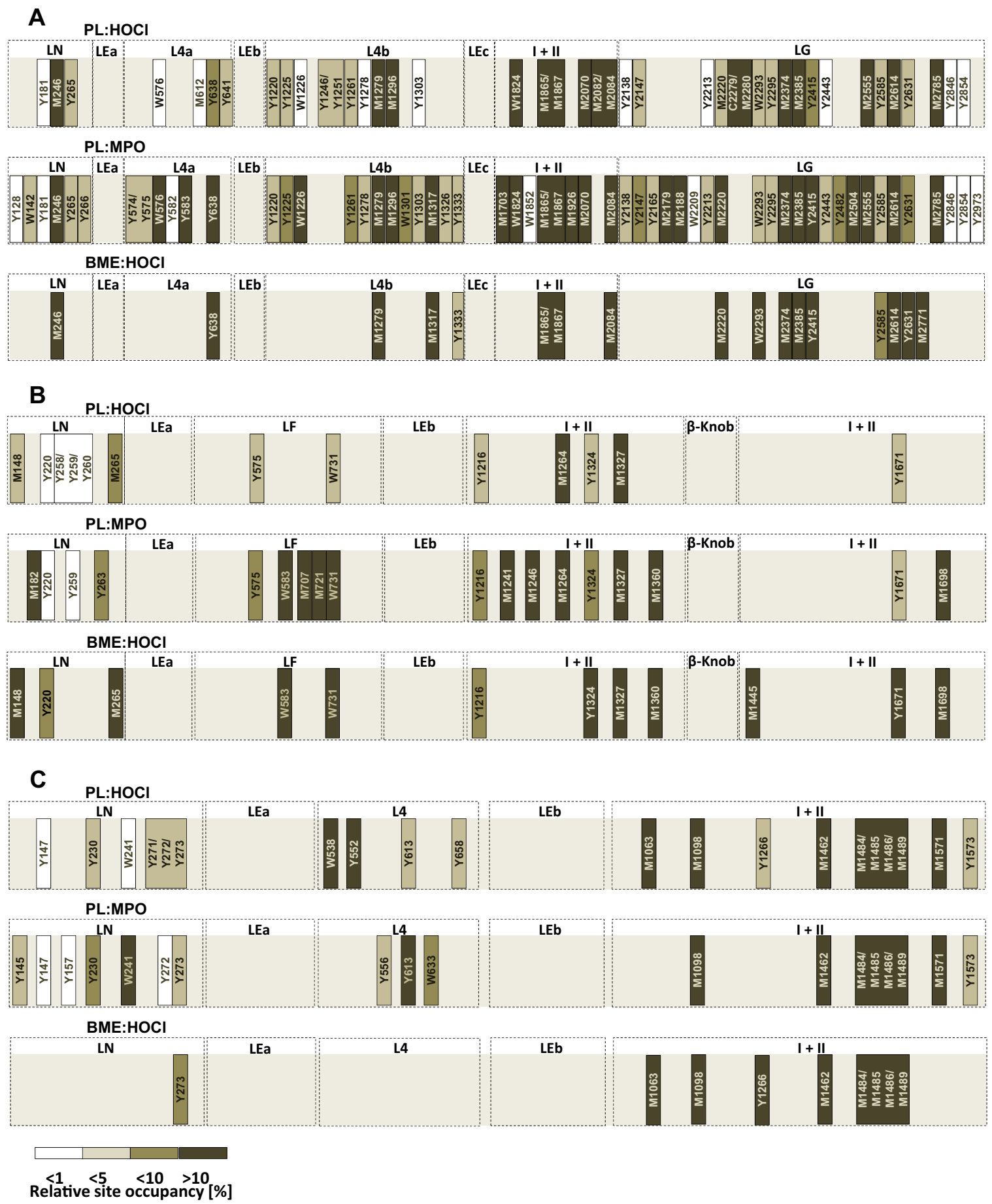

Fig. 2. Schematic of the domain structures in murine laminin-111 chains $\alpha 1$ (A), $\beta 1$ (B), and $\gamma 1$ (C) annotated with the sites of modification and numbering within sequence ( $\mathrm{Y}$, chlorination at indicated Tyr residue; $\mathrm{M}$, oxidation at indicated Met residue, $\mathrm{W}$, oxidation at indicated Trp residue) and their relative site occupancy with darker colours indicating increased extents of modification. Purified laminin- $111(2.27 \mu \mathrm{M})$ was treated with $500 \mu \mathrm{M} \mathrm{HOCl}$ or the $\mathrm{MPO} / \mathrm{H}_{2} \mathrm{O}_{2} / \mathrm{Cl}^{-}$system with $500 \mu \mathrm{M} \mathrm{H}_{2} \mathrm{O}_{2}$. Murine basement membrane extract (BME; $1 \mu \mathrm{g}$ protein) was treated with $500 \mu \mathrm{M} \mathrm{HOCl}$. Reactions were carried out in $100 \mathrm{mM}$ sodium phosphate buffer, $\mathrm{pH} 7.4$, for $1 \mathrm{~h}$ at $21^{\circ} \mathrm{C}$ before analysis, as indicated in the Materials and methods.

ClTyr detected, relative to $\mathrm{H}_{2} \mathrm{O}_{2}$ initially supplied (and hence $\mathrm{HOCl}$ formed), indicates that this product accounts for $\sim 0.22 \%$ of the $\mathrm{HOCl}$ generated, indicating that this is a low abundance modification, as reported previously $[23,66]$.

\subsection{Detection and quantification of $\mathrm{MPO} / \mathrm{H}_{2} \mathrm{O}_{2} / \mathrm{Cl}^{-}$-induced modifications} on laminin using ELISA

Previous studies have employed a monoclonal antibody, 2D10G9, to detect HOCl-induced damage in biological samples (e.g. 


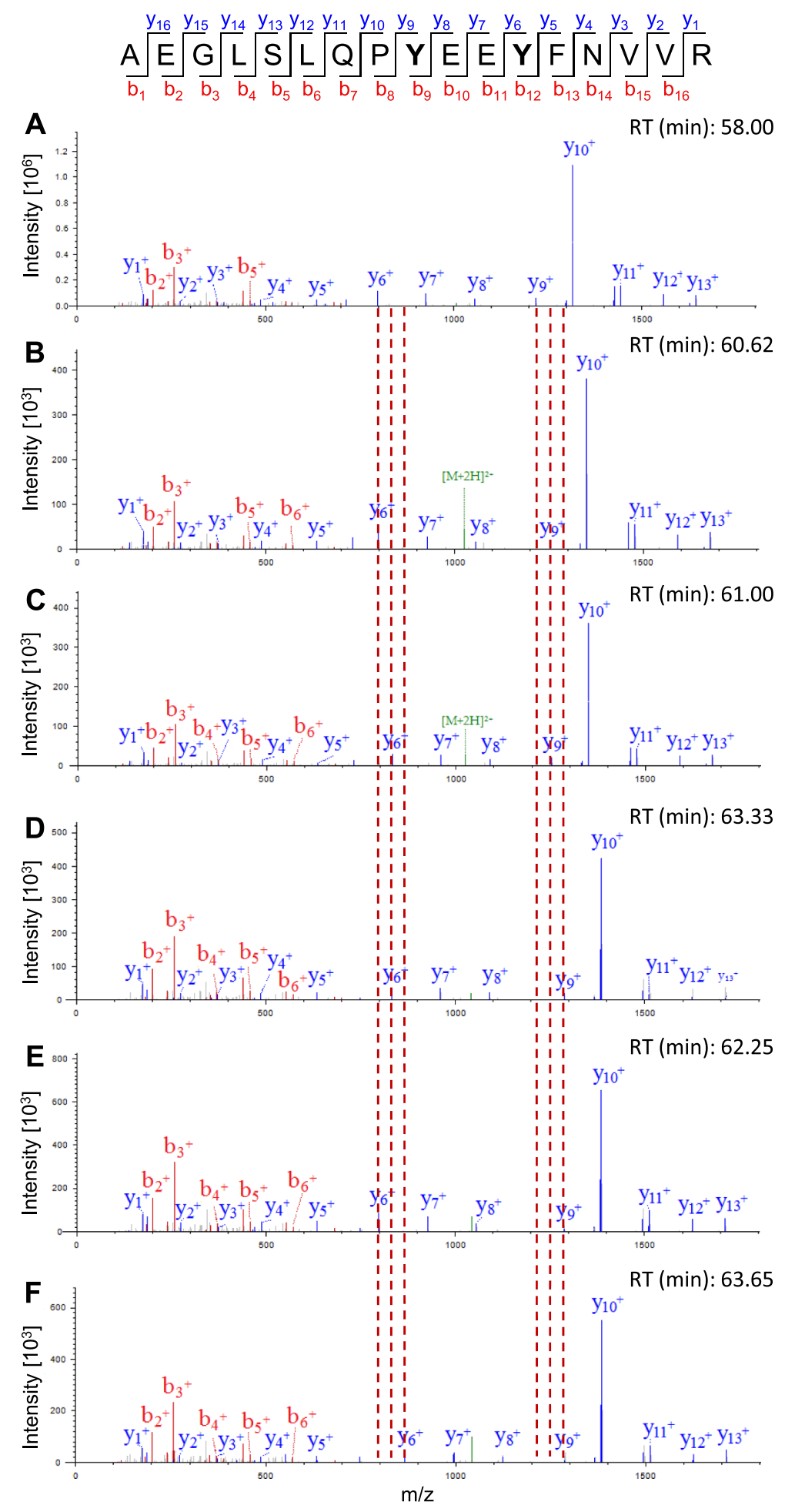

Fig. 3. Fragment ion spectra of laminin $\alpha 1$ peptide ${ }_{630}$ AEGLSLQPYEEYFNVVR $_{646}$. (A) without modification, with single chlorination at $\operatorname{Tyr}_{638}$ (B), $\operatorname{Tyr}_{641}(\mathrm{C})$, or both $\operatorname{Tyr}_{638}$ and $\operatorname{Tyr}_{641}$ (D), and dichlorination at $\operatorname{Tyr}_{638}(\mathrm{E})$, or dichlorination at $\mathrm{Tyr}_{641}(\mathrm{~F})$. Grey lines indicate the $\mathrm{y}_{6}$ and $\mathrm{y}_{9}$ ions showing mass shifts diagnostic for $\mathrm{Cl}$ ( $+34 \mathrm{Da}$ ) and $\mathrm{Cl}_{2}$ ( $+68 \mathrm{Da}$ ) on $\mathrm{Tyr}_{638}$ and $\mathrm{Tyr}_{641}$, respectively. Retention time (RT) designates the time of elution for the given peptide. Data obtained from murine laminin-111 (1.18 $\mu \mathrm{M})$ treated with $0.1 \mu \mathrm{M} \mathrm{MPO}, 500 \mu \mathrm{M} \mathrm{H}_{2} \mathrm{O}_{2}$, and $100 \mathrm{mM} \mathrm{NaCl}$. Annotated MS/MS spectra and fragment ion tables for all identified peptides are presented in Supplementary Fig. 4.
$[16,35,58,59,67]$. This antibody was therefore used to examine the formation of $\mathrm{MPO} / \mathrm{H}_{2} \mathrm{O}_{2} / \mathrm{Cl}^{-}$-induced epitopes on both isolated laminin111 using an ELISA assay, and also the presence of these epitopes in human atherosclerotic lesions (see below) by immunofluorescence.

Treatment of isolated laminin- 111 with the $\mathrm{MPO} / \mathrm{H}_{2} \mathrm{O}_{2} / \mathrm{Cl}^{-}$system, with varying amounts of $\mathrm{H}_{2} \mathrm{O}_{2}$, provided evidence for HOCl-generated epitopes on laminin, detected by the 2D10G9 antibody, with greater recognition observed with higher oxidant doses with statistically-significant increases in recognition detected with the complete enzyme system containing $\geq 10 \mu \mathrm{M} \mathrm{H} \mathrm{H}_{2} \mathrm{O}_{2}$ (Fig. 8). Little recognition was observed for control (untreated) protein samples, or when individual components of the enzyme system were omitted (data not shown). The increase in recognition was not linear, as expected, due to the presence of other reactive targets [23] on the protein. 
A

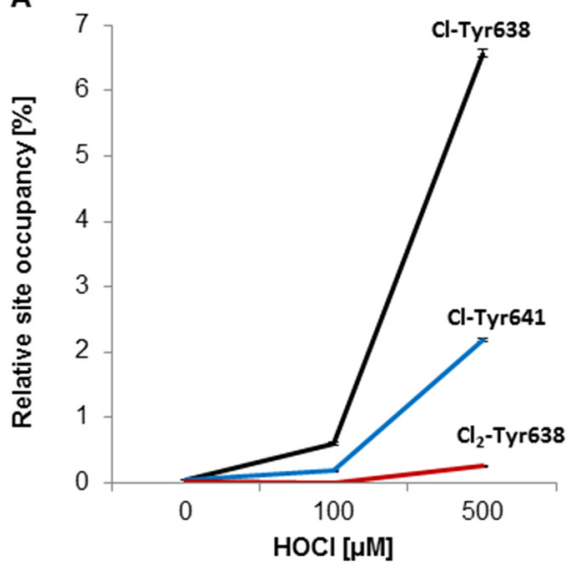

B

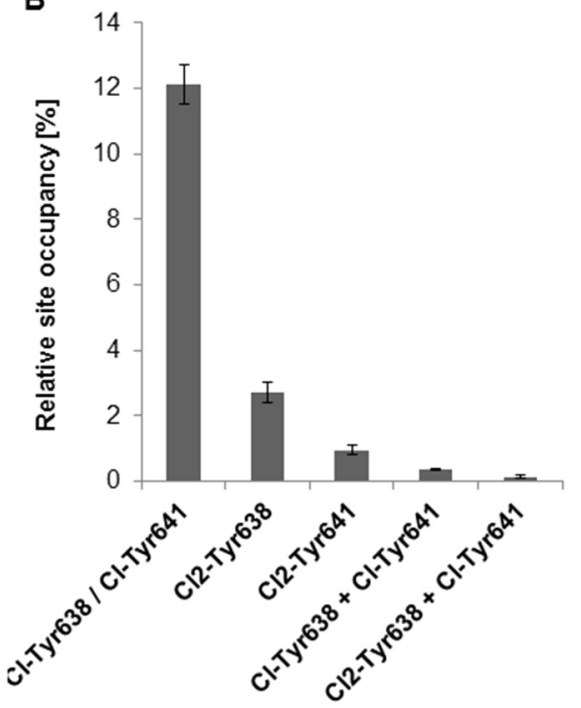

Fig. 4. (A) Dynamics of 3-ClTyr and 3,5- $\mathrm{Cl}_{2} \mathrm{Tyr}$ formation on peptide ${ }_{630} \mathrm{AEGLSLQPYEEYFNVVR}{ }_{646}$ detected on oxidation of murine laminin-111 $(1.18 \mu \mathrm{M})$ treated with 0 , 100 , and $500 \mu \mathrm{M} \mathrm{HOCl}$. (B) Relative site occupancy of different chlorination products detected at $\mathrm{Tyr}_{638}$ and $\operatorname{Tyr}_{641}$ on treatment of murine laminin-111 $(1.18 \mu \mathrm{M})$ with $0.1 \mu \mathrm{M}$ MPO, $500 \mu \mathrm{M} \mathrm{H}_{2} \mathrm{O}_{2}$, and $100 \mathrm{mM} \mathrm{NaCl}$.

\subsection{Structural changes induced on laminin by exposure to reagent $\mathrm{HOCl}$ and a MPO enzyme system}

The above data indicate that $\mathrm{HOCl}$ and the $\mathrm{MPO} / \mathrm{H}_{2} \mathrm{O}_{2} / \mathrm{Cl}^{-}$system can induce significant changes on laminin-111 at the residue level. Whether these modifications result in structural changes was examined using SDS-PAGE with silver staining (under both non-reducing and reducing conditions) or immunoblotting using an anti-murine laminin antibody (clone AL-2).

SDS-PAGE carried out under non-reducing conditions on samples treated with both $\mathrm{HOCl}$ (Fig. 9A) and the $\mathrm{MPO} / \mathrm{H}_{2} \mathrm{O}_{2} / \mathrm{Cl}^{-}$system (Fig. 9C), resulted in the detection, by silver staining, of large amounts of material which migrated only a short distance into the gels from the loading wells, consistent with the presence of high molecular mass, intact trimeric laminin-111 protein (Fig. 9A). This material was not detected under reducing conditions (Fig. 9B,D). Increasing oxidant exposure resulted in modest smearing of this band to lower masses, with this being most obvious for the $\mathrm{HOCl}$ system (Fig. 9A). Under non-reducing conditions, weaker bands were detected at $\sim 460 \mathrm{kDa}$ (assigned to low levels of dissociated $\alpha 1$ chains; red arrows) and $\sim 200 \mathrm{kDa}$ (blue arrows; assigned to $\beta 1$ and $\gamma 1$ chains which have similar masses). These bands do not correspond to the masses indicated by the molecular mass standards (Fig. 9A,C), as the markers are reduced protein samples, which migrate at a different rate to the non-reduced proteins. On the reducing gels (Fig. 9B,D), these lower mass bands migrate at approximately the expected masses. With increasing oxidant exposure the intensity of the staining of the bands assigned to the $\alpha 1, \beta 1$ and $\gamma 1$ chains decreased. These changes were more marked for the samples run under non-reducing conditions, presumably due to the lower concentrations of the protein present in a dissociated form. The bands assigned to the parent $\alpha 1, \beta 1$ and $\gamma 1$ chains showed increased smearing with higher oxidant exposure, with this being ascribed to the presence of multiple proteins conformations, and/or modest changes in molecular mass, arising from oxidation. A weak band was also detected at low molecular mass on the reducing gels (Fig. 9B,D), with the staining intensity of this band increasing with increasing oxidant exposure for both the $\mathrm{HOCl}$ and enzyme systems. The origin of this material is unclear, though it may be a protein fragment induced by oxidation that is only released and detected under reducing conditions, possibly as a result of disulfide bond cleavage.
Immunoblotting of samples separated under reducing conditions with the rat anti-murine laminin antibody (clone AL-2), provided evidence, for the HOCl system (Fig. 9E), for reduced recognition of the $\alpha 1$ chain on increasing $\mathrm{HOCl}$ exposure. The $\beta 1$ and $\gamma 1$ chains did not give rise to significant signals, possibly as a result of the preferential recognition of $\alpha 1$ chain epitopes by this antibody. Corresponding blots were not carried out on samples separated under non-reducing conditions due to the low intensity of the bands from the dissociated chains, and the poor migration of the trimeric protein. Immunoblotting experiments with the 2D10G9 antibody did not provide usable data, consistent with previous experience with this antibody and gels (Chuang et al., unpublished data).

\subsection{In vivo evidence for laminin modification by the $\mathrm{MPO} / \mathrm{H}_{2} \mathrm{O}_{2} / \mathrm{Cl}^{-}$ system}

As laminins are major proteins of the BM that underlies the endothelial cells of the artery wall, and the evidence for HOCl-mediated damage during the development of atherosclerosis $[15,26,35,36]$, we sought evidence for the presence of laminin, and HOCl-mediated damage to laminin, in human atherosclerotic lesions. Examination of frozen sections of type II-IV human lesions demonstrated the presence of high levels of laminin detected by a monoclonal antibody that recognises laminin $\gamma 1$ in the BM underlying the endothelial cells (Fig. 10A-C, left panel) and also in the BM of smaller vasa vasorum in deeper regions of the tissue (Fig. 10C, left panel). When the same tissue sections were stained for $\mathrm{HOCl}$-generated epitopes, strong fluorescence was detected in similar regions (Fig. 10A-C, middle panel). In addition to staining near the surface of the aortae, consistent with the BM, areas of the vasa vasorum also showed pronounced positivity for $\mathrm{HOCl}-$ modifed epitopes (Fig. 10A-C, middle panel). Merging of images from Fig. 10A-C (left and middle panel) reveal intense staining for laminin and HOCl-modified epitopes in close proximity with partial colocalization within the BM underneath the endothelial layers of the aortae (Fig. 10A-C, right panel) as well as the endothelial layers of vasa vasorum (Fig. 10C, right panel). Control experiments in which the primary antibodies were omitted, or experiments using non-immune mouse or rabbit IgG, showed no artefactual staining (data not shown). 


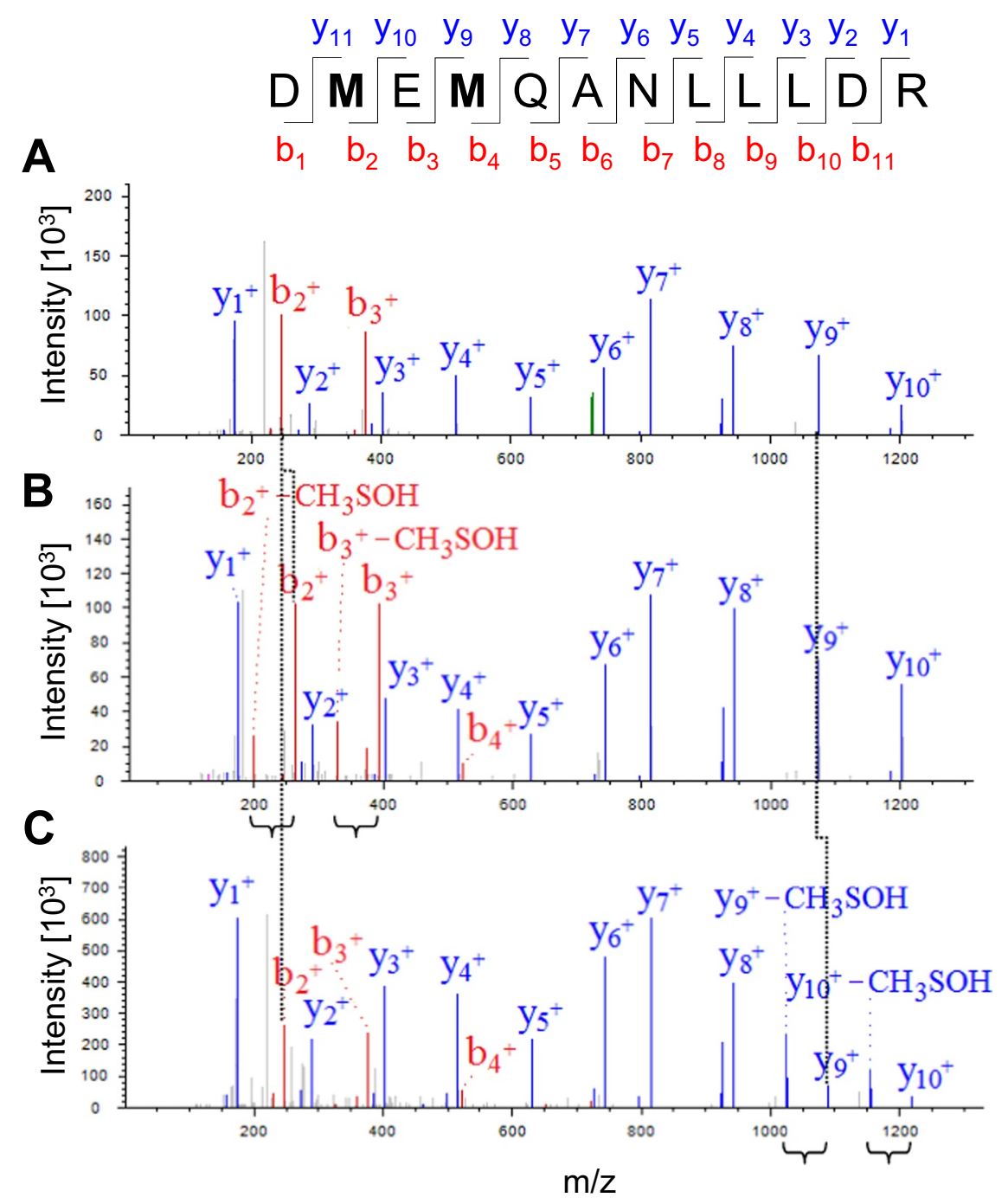

Fig. 5. Fragment ion spectra of the peptide ${ }_{2081}$ DMEMQANLLLDR $_{2092}$ from murine laminin-111 for: (A) the native peptide, (B), peptide with mono-oxygenation (sulfoxide formation) at $\mathrm{Met}_{2082}$, and (C) peptide with mono-oxygenation (sulfoxide formation) at Met $_{2084}$. Data from murine laminin-111 (1.18 $\mu \mathrm{M}$ ) treated with 0 , 100, and $500 \mu \mathrm{M} \mathrm{HOCl}$. Annotated MS/MS spectra and fragment ion tables for all identified peptides are available in Supplementary Fig. 4.
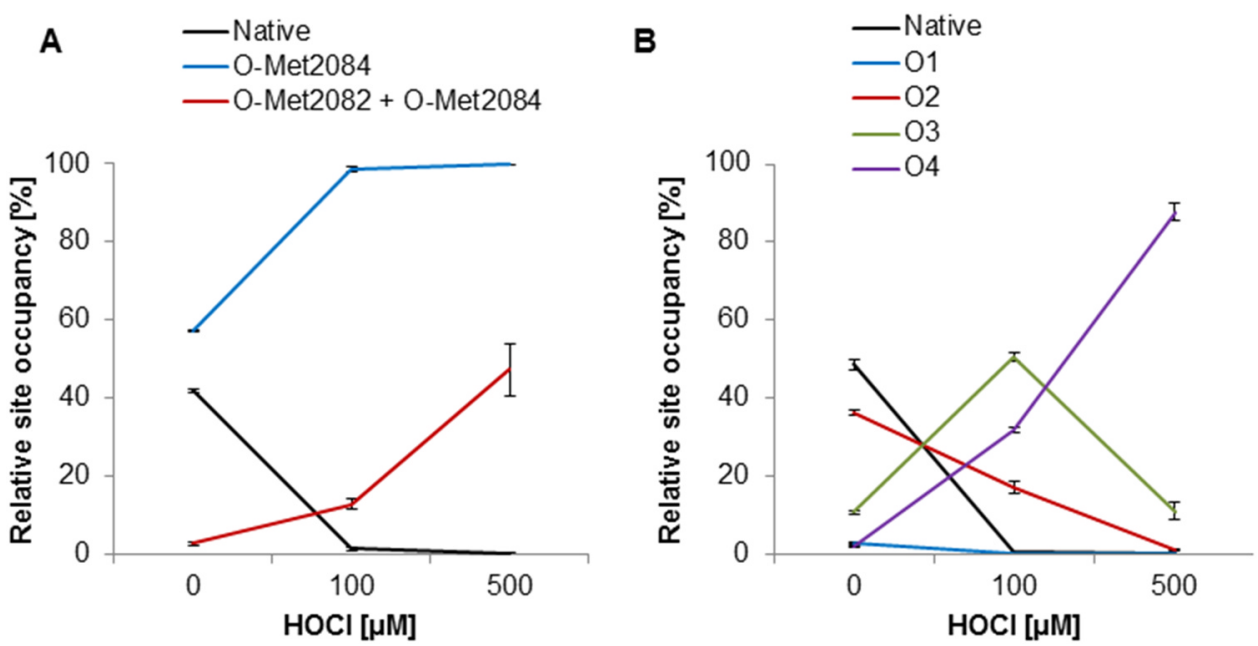

Fig. 6. Concentration dependence of modifications at Met residues in the peptides: (A) ${ }_{2081}$ DMEMQANLLLDR $_{2092}$ and (B) ${ }_{1476}$ KQDDADQDMMMAGMASQAAQEAELNAR ${ }_{1502}$. In (A), the Met residues at position 2084 and 2082 appear to be modified sequentially and in this order. In (B), modification occurs at each of the 4 Met residues with little apparent site specificity at any of the Met residues. With increasing $\mathrm{HOCl}$ exposure all 4 Met residues become oxidised. Data from murine laminin$111(1.18 \mu \mathrm{M})$ treated with 0,100 , and $500 \mu \mathrm{M}$ $\mathrm{HOCl}$ as indicated. 

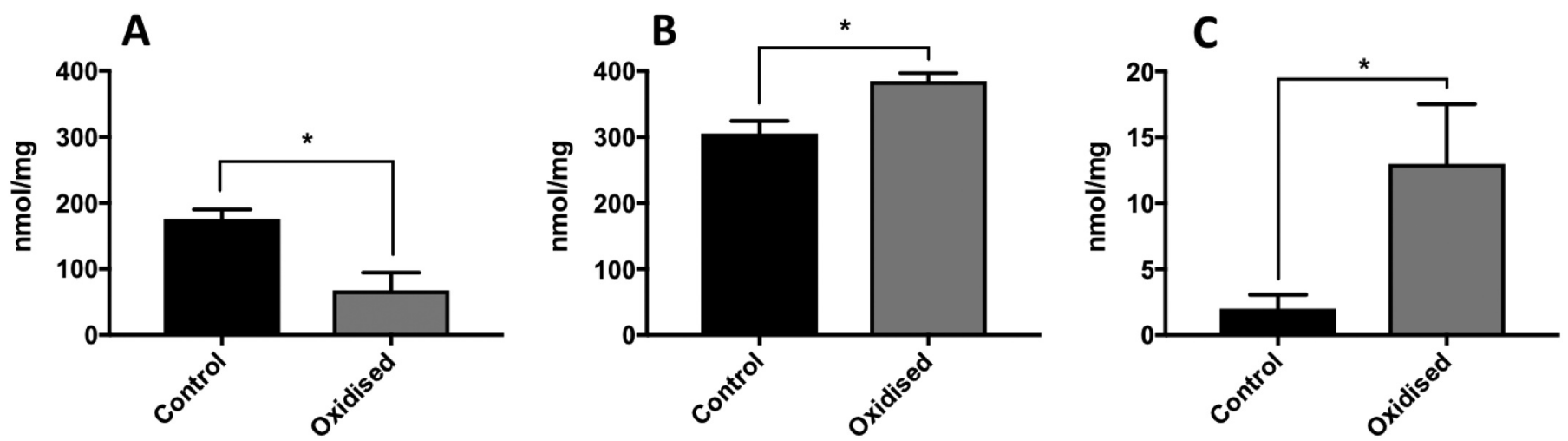

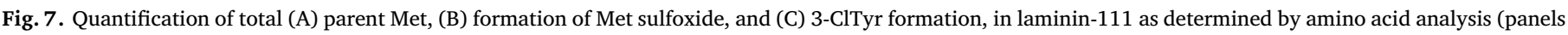

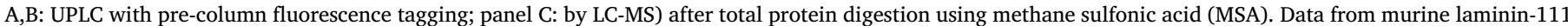

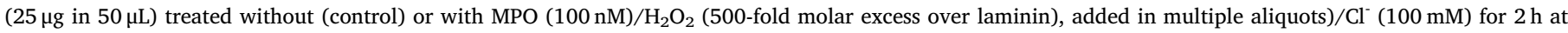

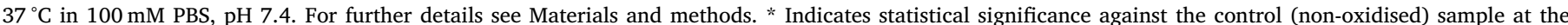

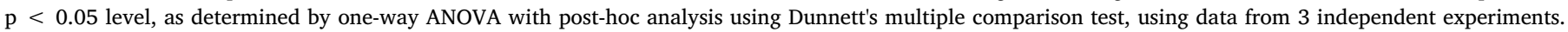

\section{Discussion}

Previous studies have provided compelling evidence for a strong association between the levels of MPO (which is released by activated phagocytes at sites of inflammation), and the oxidants it generates, with the development of atherosclerosis (e.g. [15,16,26,28,32,35,68,69]. Rupture of atherosclerotic lesions is a major cause of heart attack and stroke, and sudden cardiac death. It has been shown that blood or plasma/serum levels of MPO can be both diagnostic of major cardiovascular diseases, and predictive of adverse outcomes (e.g. [28,30,70]). As MPO is released from intracellular storage granules into phagolysosomes or extracellularly [22], and binds strongly to ECM components $[61,71]$, it would be expected that the oxidants generated by this enzyme would target matrix materials. Considerable data support this hypothesis $[42,48,61,62,71]$. Evidence has also been presented for ECM damage by other oxidants associated with both normal metabolism and inflammation, such as peroxynitrous acid, and for the presence of

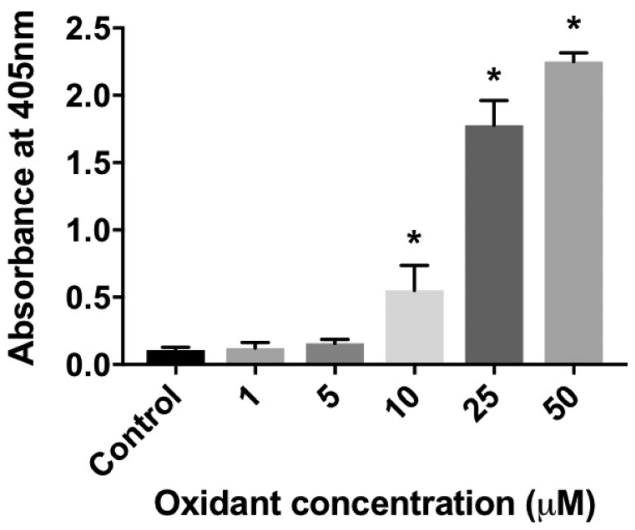

Fig. 8. Detection of HOCl-mediated damage to laminin-111 incubated with a $\mathrm{MPO} / \mathrm{H}_{2} \mathrm{O}_{2} / \mathrm{Cl}^{-}$system by use of ELISA employing the monoclonal antibody 2D10G9. Laminin-111 (25 $\mu \mathrm{g}$ in $50 \mu \mathrm{L}$ ) was treated with MPO $(20 \mathrm{nM}) / \mathrm{H}_{2} \mathrm{O}_{2}$ (at the indicated concentrations, added in multiple aliquots) $/ \mathrm{Cl}^{-}(100 \mathrm{mM})$ for $2 \mathrm{~h}$ at $37^{\circ} \mathrm{C}$ in $100 \mathrm{mM}$ PBS, pH 7.4. Samples were then probed for epitopes recognised by 2D10G9 as described in the Materials and methods and determination of the absorbance at $405 \mathrm{~nm}$. * Indicates statistical significance against the control (non-oxidised) sample at the $\mathrm{p}<0.05$ level, as determined by oneway ANOVA with post-hoc analysis using Dunnett's multiple comparison test, using data from 3 independent experiments. modified ECM species in human atherosclerotic lesions (e.g. $[6,7,9-11,72])$. However the exact nature, sites and extents of modification induced by MPO and its oxidants (e.g. HOCl) on ECM materials such as laminin, the major basement membrane protein, are poorly characterized. As a consequence we have determined the sites and extent of oxidation and chlorination induced by both reagent $\mathrm{HOCl}$ and the $\mathrm{MPO} / \mathrm{H}_{2} \mathrm{O}_{2} / \mathrm{Cl}^{-}$system on purified laminin-111, and this protein present in BME. We have also examined possible structural changes induced by oxidant exposure, and the potential presence of $\mathrm{HOCl}-$ modified laminins in human atherosclerotic lesions.

The data obtained indicate that some sites on laminin-111 are more susceptible to modification than others, as judged by both the sitespecificity and extent of modification as determined by RSO. Treatment with reagent $\mathrm{HOCl}$ resulted in the detection, by MS mass mapping, of oxidation at 30 Met and 7 Trp residues, and chlorination of $33 \mathrm{Tyr}$ residues (with $3 \mathrm{Tyr}$ also detected as 3,5- $\mathrm{Cl}_{2} \mathrm{Tyr}$ ), out of the $56 \mathrm{Met}, 24$ Trp and 99 Tyr residues present in the native protein. Treatment of the isolated laminin-111 with the $\mathrm{MPO} / \mathrm{H}_{2} \mathrm{O}_{2} / \mathrm{Cl}^{-}$system, supplied with $500 \mu \mathrm{M} \mathrm{H}_{2} \mathrm{O}_{2}$ to give $\sim 500 \mu \mathrm{M} \mathrm{HOCl}$, showed some similarities, and also some significant differences, with the regard to the both the sites and extents of modification. This may be due to an association or binding of MPO to particular sequences within the trimeric laminin structure. A recent study, using an identical MS approach, quantified modifications induced by reagent $\mathrm{HOCl}$, versus $\mathrm{MPO} / \mathrm{H}_{2} \mathrm{O}_{2} / \mathrm{Cl}^{-}$on human plasma fibronectin, showed an overall decrease in the number of sites, and extent of modification, [48]. In contrast, for laminin, a significant increase in the number of sites, and a greater extent of modification were observed with $\mathrm{MPO} / \mathrm{H}_{2} \mathrm{O}_{2} / \mathrm{Cl}^{-}$compared to $\mathrm{HOCl}$. Thus, an additional $8 \mathrm{Met}$ and $10 \mathrm{Trp}$ oxidation sites, and 14 3-ClTyr, and 18 3,5- $\mathrm{Cl}_{2} \mathrm{Tyr}$ positions were detected with $\mathrm{MPO} / \mathrm{H}_{2} \mathrm{O}_{2} / \mathrm{Cl}^{-}$with an identical initial amount of added $\mathrm{H}_{2} \mathrm{O}_{2}$ (and hence $\mathrm{HOCl}$ formed, as judged by the quantification of oxidant formation using monochlorodimedone or $3,3^{\prime}, 5,5^{\prime}$-tetramethylbenzidine [48]). This increase in number and extent of modifications is surprising, as MPO protein might be expected to act as an alternative target for the generated oxidant, and therefore diminish the oxidant concentration available for reaction with the laminin. It is unclear, at present, why there are these differences. It is possible that interactions between MPO and the ECM proteins, results in a higher concentration or efficiency of oxidant formation in the case of association with laminin, and/or that association of MPO with fibronectin inhibits MPO activity and thereby decreases the extent of fibronectin modification (cf. the inhibition, via complex formation of plasma ceruloplasmin on MPO activity $[73,74]$ ).

Both the MS and amino acid analyses indicate that Met residues are 


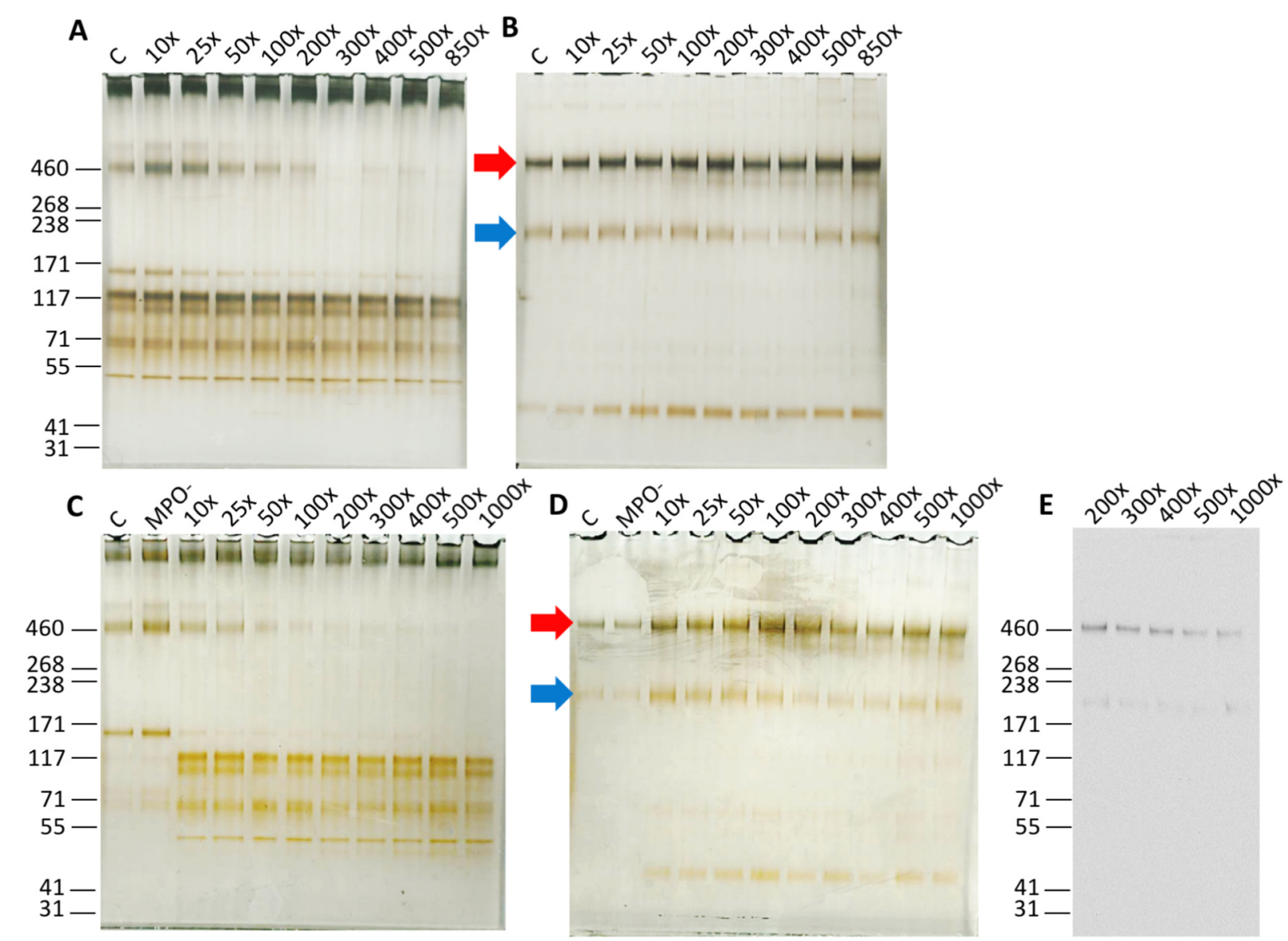

Fig. 9. Structural changes induced on laminin- 111 and individual laminin chains induced by reagent $\mathrm{HOCl}$ (panels A,B) or a $\mathrm{MPO} / \mathrm{H}_{2} \mathrm{O}_{2} / \mathrm{Cl}^{-}$system (panels C,D) detected by SDS-PAGE run under non-reducing (panels A,C) or reducing conditions (panels B,D) with detection of protein bands by silver staining. Laminin-111 $\left(2.5 \mu \mathrm{g}\right.$ in $50 \mu \mathrm{L}$ ) was treated with reagent $\mathrm{HOCl}$ at the indicated molar excesses (panels A,B) or for panels (C,D) with a MPO $(100 \mathrm{nM}) / \mathrm{H}_{2} \mathrm{O}_{2}($ at the indicated molar excesses, added in multiple aliquots)/Cl' $(100 \mathrm{mM})$ system for $2 \mathrm{~h}$ at $37^{\circ} \mathrm{C}$ in $100 \mathrm{mM} \mathrm{PBS}$, pH 7.4, before analysis. In panels A-D, the lane labelled "C" is control, nonoxidised protein. In panels C,D, the lane labelled "MPO-" is the complete reaction system without MPO (i.e. laminin incubated with $\mathrm{H}_{2} \mathrm{O}_{2}$ alone). The extreme left lane (and extreme right lane for panels $\mathrm{A}, \mathrm{B}$ ) on each gel contains molecular mass markers for reduced proteins of the indicated masses. Red arrows indicate the bands assigned to the $\alpha 1$ chains, and the blue arrows indicate bands assigned to the $\beta 1$ and $\gamma 1$ chains that have very similar masses. Panel E: Reaction system as panel B (i.e. treatment of laminin-111 with reagent $\mathrm{HOCl}$ at the indicated molar excesses, and SDS-PAGE separation run under reducing conditions) except the resulting gel was blotted and probed for recognition of laminin chains using a rat anti-murine laminin monoclonal antibody (clone AL-2) and subsequent chemiluminescence detection (for details see Materials and methods). The major band detected is from the $\alpha 1$ chain. Representative gels and blots are presented, typical of 3 independent experiments.

a major target for $\mathrm{HOCl}$ with this protein; this is in accord with the high rate constant for reaction of $\mathrm{HOCl}$ with this side-chain $(k$ $3 \times 10^{7}-1 \times 10^{8} \mathrm{M}^{-1} \mathrm{~s}^{-1}[23,75]$. Cys and cystine are also highly reactive with $\mathrm{HOCl}[23,75,76]$, with $k$ for Cys (typically) higher than for Met [75]. However, there is a very low abundance of Cys (but a moderate number of cystine) residues in laminin, and other ECM proteins in general, suggesting that these do not consume a significant amount of the $\mathrm{HOCl}$ provided. This does not however preclude reaction at the few Cys residues being functionally important. The rate constants, $k$, for reaction of $\mathrm{HOCl}$ with disulfides vary significantly with their environment (e.g. presence of neighboring groups) and conformation [76], suggesting that the cystine groups present in the laminin EGF-like (EL) domains of laminin may be significant targets. Reaction at such sites is however difficult to detect and quantify due to the cross-linked nature of these structures, and the destruction of these modifications during the standard "reduce and alkylate" protocols of most MS mass mapping approaches. New approaches are therefore needed to test this suggestion.

The quantitative data obtained from the amino acid analyses indicate that $\sim 15 \%$ of the $\mathrm{HOCl}$ generated by the enzyme system, is consumed by Met residues. 3-ClTyr formation accounts for an additional $\sim 0.2 \%$, with an additional (not quantified) small amount used to convert 3-ClTyr to 3,5-diClTyr. A similar analysis was not carried out for Trp. These data, together with that from the MS mass mapping, indicate that the products detected account for only a modest amount of the $\mathrm{HOCl}$ added or generated. A significant proportion of the "missing" $\mathrm{HOCl}$ is likely to have reacted with Lys, His (and possibly Arg) residues, as these are important kinetic targets [23,24], and highly abundant in laminin-111 (cf. 316 Lys, 161 His residues; data from Uniprot entries P19137, P02469, P02468). Reaction at these residues gives unstable chloramines (RNHCl species, and dichloramines, $\mathrm{RNCl}_{2}$, at higher oxidant concentrations) that decay over minutes-hours. Decomposition of these species yields multiple materials, including regeneration of the parent amino acid, radicals [77,78], carbonyl compounds [77,79-81], 

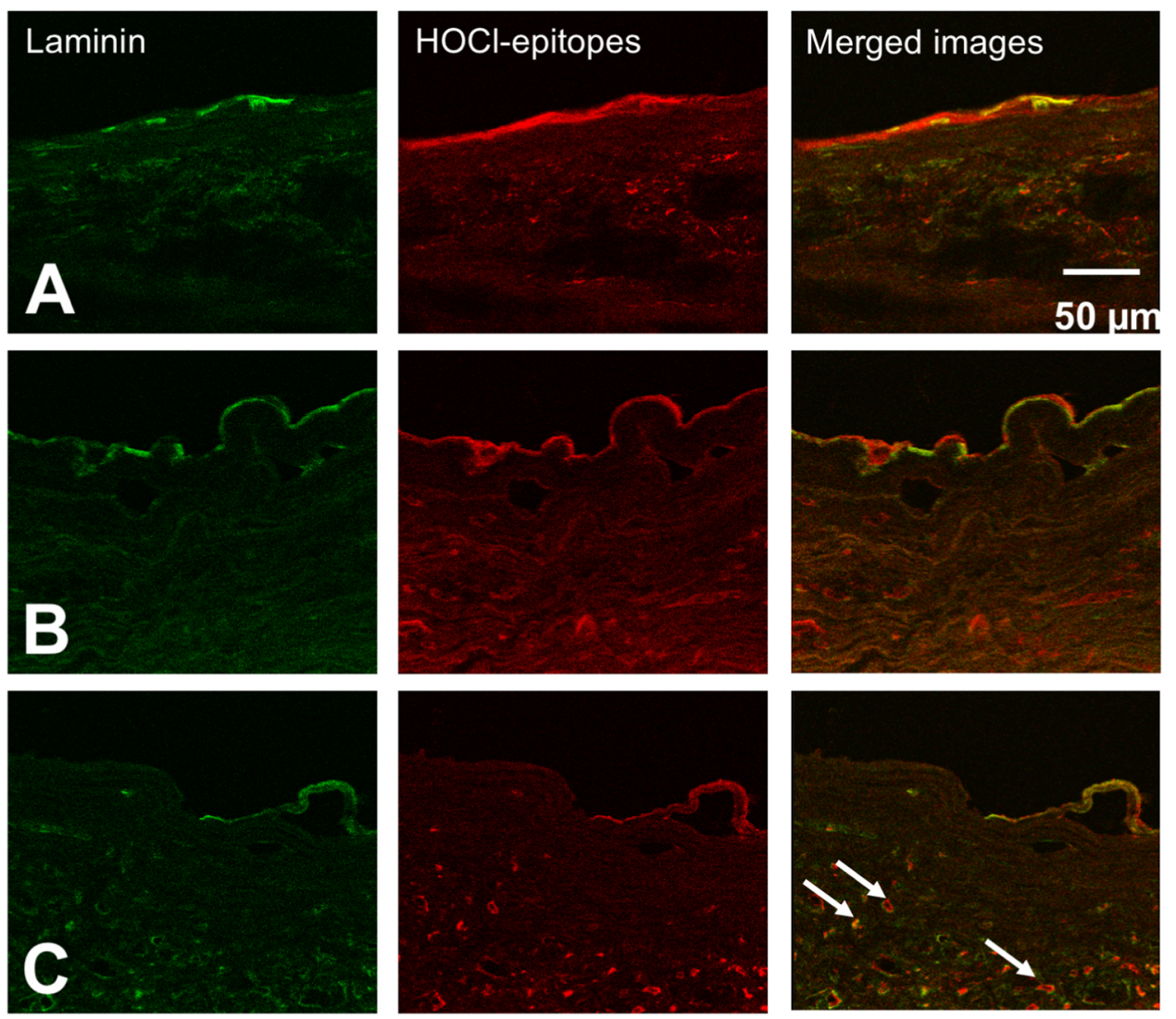

Fig. 10. Immunofluorescence staining for laminin and HOCl-modified proteins and co-localization in human type II-IV atherosclerotic lesions. Five $\mu \mathrm{m}$ frozen sections of arteria femuralis (A, autopsy material of a 80-year-old female patient, type II-III; $B$, autopsy material of a 56-year-old female patient, type II-III) and aorta abdominalis (C, autopsy material of a 74year-old male patient, type III-IV) were incubated with anti-laminin mAb (clone 2E8, Merck-Millipore, dilution 1:100, A-C, left panel) and detected with a goat anti-mouse Cy2 labelled antibody (1:300, green). HOClmodified proteins were detected using Cy-3labelled monoclonal antibody (clone 2D10G9, dilution 1:100, red, A-C, middle panel). Right panels (A-C) show the resulting overlay (merge) of laminin (green) and HOCl-modified proteins (red). White arrows indicate vasa vasorum. carboxylic acids [82], and nitriles [82]. This complexity makes quantification complex [77-79].

Mapping of the detected modifications onto a complete 3D structure cannot be accomplished at present, as only a small number of partial structures are available. A recently structure (PDB entry: 5MC9) [83] contains the coordinates of the xLG1-3 domains, as well as $\sim 50$ residues of the coiled coil $(\alpha 1 \beta 1 \gamma 1)$. These sequences contain $20 \mathrm{Tyr}$, of which 11 were identified as chlorination targets, 14 Met, of which 7 were detected as sulfoxides, and 4 Trp, with 3 of these detected as oxidised species (Fig. 11A, Supplementary Fig. 8). While most of these modified residues appear to be surface exposed, $\mathrm{Tyr}_{2138}, \mathrm{Tyr}_{2147}$, $\mathrm{Trp}_{2293}, \mathrm{Tyr}_{2295}$, and $\mathrm{Met}_{2554}$, which were detected as modified species with both $\mathrm{HOCl}$ and $\mathrm{MPO} / \mathrm{H}_{2} \mathrm{O}_{2} / \mathrm{Cl}^{-}$, appear to be buried within the structure; this is also true for Met $_{2179}$, which was modified solely by the enzyme system. These data indicate either that (neutral) $\mathrm{HOCl}$ can penetrate and react within the interior of a protein, or that the crystal structure represents a "snap shot" of a system with considerable flexibility. The detection of modifications to (surface-exposed) $\mathrm{Tyr}_{2415}$ is of particular interest as it is situated close to $\mathrm{Glu}_{1605}$ (indicated in brown, in Fig. 11, panel A), which is essential for interactions with integrins [83-85]. Modification of this residue, and possibly others nearby, may therefore affect integrin binding to laminins, and hence cell binding to the ECM $[4,85]$.

Similar analyses (Fig. 11, panels B-E) have been carried out using the structures of the short arms of the $\beta 1$ and $\gamma 1$ chains (PDB entries: 4AQS and 4AQT [86]), which contain both the $N$-terminal (LN) and part of the first EL-like domains. As little sequence coverage (and hence no modifications) was obtained for the LE domains due to the presence of disulfide bonds (cf. Fig. 1), the renderings of these structures are displayed both with the LE domains included, and with these greyed out (Fig. 11B-E). The $\beta 1$ structure contains 12 Tyr, 5 Met, and 4 Trp residues, with 3-ClTyr formation detected at 3 Tyr (Tyr-220, Tyr-259, Tyr 263) and sulfoxide formation at 3 Met (Met-148, Met-182, Met265). The $\gamma 1$ structures contains 13 Tyr, 2 Met, and 4 Trp, with 4 of the Tyr residues detected as 3-ClTyr (Tyr-145, Tyr-230, Tyr-272, Tyr-273). Interestingly, the sites that were most readily modified are, in general, not those that are most surface-exposed. The majority of the modifications detected are present in the highly conserved portions of both structures that appear to be involved in binding to other chains [86]. Laminin polymerisation has been proposed to occur, at least in vitro, via a two-step process initiated by association of the $\beta$ and $\gamma$ chains through the LN-terminal domains, followed by association with the $\alpha$ chains [87], so these data suggest that the ECM assembly may be affected by modifications in the LN domains.

The LE domains contain a large number of Tyr and Trp residues, which may be potential modification targets overlooked by the current method. The LE domains are highly preserved structural elements present in a wide array of extracellular proteins $[88,89]$, and are known to mediate in the case of laminin $\gamma 1$, binding to other BM materials such as nidogen [90]. Modification to the LE domains may therefore have functional consequences and stresses the need for efficient methods to analyse disulfide-rich peptides. 

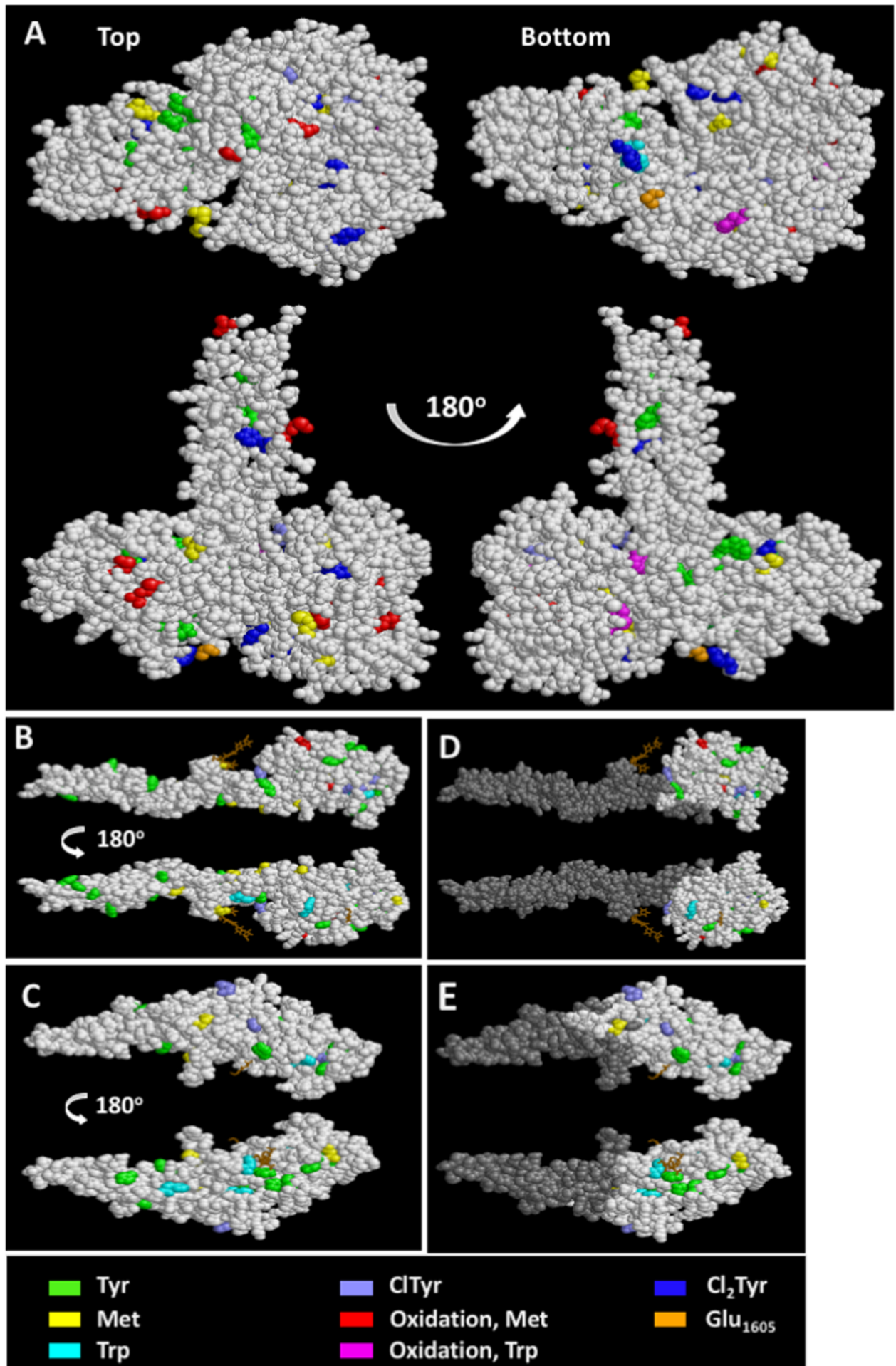

The potential functional importance of these modifications is indicated by enhanced recognition of modified laminin-111 by the 2D10G9 antibody that recognises HOCl-mediated damage (Fig. 9), and the detection of material recognised by this antibody in human type IIIV atherosclerotic lesions (Fig. 10). The close co-localization of epitopes recognised by 2D10G9 with those recognised by a laminin antibody in human lesion material provides strong support for the presence of HOCl-modified laminin and other extracellular matrix materials in this
Fig. 11. Mapping of all (parent and modified) Tyr, Met and Trp residues (colour coded as indicated) onto (A) the crystal structure (data from PDB entry: 9MC5) of the LG1-3 domain and the first 50 residues of the coiled-coil, (B, $D)$ the LN domain of the $\beta 1$ chain (PDB entry: 4AQS) and (C, E) the LN domain of the $\gamma 1$ chain (PDB entry: 4AQT). Attached glycan chains are indicated as brown stick structures, and the key integrin binding residue $\mathrm{Glu}_{1605}$ (panel A) are also indicated. For the $\beta 1$ and $\gamma 1$ structures presented in panels $\mathrm{D}$ and $\mathrm{E}$, the residues that interact with the LE domains (and hence might be expected to be protected from modification in the entire protein structure), are indicated in grey. The indicated modifications at Tyr, Met and Trp are those induced by treatment of murine laminin-111 $(1.18 \mu \mathrm{M})$ with $0.1 \mu \mathrm{M} \mathrm{MPO}$ and $500 \mu \mathrm{M} \mathrm{H}_{2} \mathrm{O}_{2}$, in the presence of $100 \mathrm{mM} \mathrm{NaCl}$, in $100 \mathrm{mM}$ PBS, pH 7.4 , for $1 \mathrm{~h}$. 


\section{Acknowledgements}

The authors are grateful to the Novo Nordisk Foundation (Grant NNF13OC0004294) and the Danish Council for Independent Research (Det Frie Forskningsråd, Grant DFF-7014-00047) for financial support. ARW was supported by Independent Research Fund Denmark - Natural Sciences (FNU) and VILLUM Foundation grant to the VILLUM Center for Bioanalytical Sciences at SDU. The research leading to these results has received funding from the People Programme (Marie Curie Actions) of the European Union's Seventh Framework Programme (FP7/ 2007-2013) under REA grant agreement no. 608765 (Fellowship to LFG) and the Austrian National Bank (OeNB 17600).

\section{Appendix A. Supplementary material}

Supplementary data associated with this article can be found in the online version at doi:10.1016/j.redox.2018.10.022.

\section{References}

[1] T.N. Wight, M.J. Merrilees, Proteoglycans in atherosclerosis and restenosis: key roles for versican, Circ. Res. 94 (2004) 1158-1167.

[2] T.N. Wight, Arterial wall, in: W.D. Comper (Ed.), Extracellular Matrix, Harwood Academic Publishers, Amsterdam, 1996, pp. 175-202.

[3] P.D. Yurchenco, Basement membranes: cell scaffoldings and signaling platforms, Cold Spring Harb. Perspect. Biol. 3 (2011).

[4] A. Pozzi, P.D. Yurchenco, R.V. Iozzo, The nature and biology of basement membranes, Matrix Biol. 57-58 (2017) 1-11.

[5] M.D. Rees, E.C. Kennett, J.M. Whitelock, M.J. Davies, Oxidative damage to extracellular matrix and its role in human pathologies, Free Radic. Biol. Med. 44 (2008) 1973-2001.

[6] C.Y. Chuang, G. Degendorfer, M.J. Davies, Oxidation and modification of extracellular matrix and its role in disease, Free Radic. Res. 48 (2014) 970-989.

[7] C.Y. Chuang, G. Degendorfer, A. Hammer, J.M. Whitelock, E. Malle, M.J. Davies, Oxidation modifies the structure and function of the extracellular matrix generated by human coronary artery endothelial cells, Biochem. J. 459 (2014) 313-322.

[8] E.C. Kennett, M.D. Rees, E. Malle, A. Hammer, J.M. Whitelock, M.J. Davies, Peroxynitrite modifies the structure and function of the extracellular matrix proteoglycan perlecan by reaction with both the protein core and the heparan sulfate chains, Free Radic. Biol. Med. 49 (2010) 282-293.

[9] G. Degendorfer, C.Y. Chuang, A. Hammer, E. Malle, M.J. Davies, Peroxynitrous acid induces structural and functional modifications to basement membranes and its key component, laminin, Free Radic. Biol. Med. 89 (2015) 721-733.

[10] G. Degendorfer, C.Y. Chuang, H. Kawasaki, A. Hammer, E. Malle, F. Yamakura, M.J. Davies, Peroxynitrite-mediated oxidation of plasma fibronectin, Free Radic. Biol. Med. 97 (2016) 602-615.

[11] G. Degendorfer, C.Y. Chuang, M. Mariotti, A. Hammer, G. Hoefler, P. Hagglund, E. Malle, S.G. Wise, M.J. Davies, Exposure of tropoelastin to peroxynitrous acid gives high yields of nitrated tyrosine residues, di-tyrosine cross-links and altered protein structure and function, Free Radic. Biol. Med. 115 (2018) 219-231.

[12] G.K. Hansson, P. Libby, I. Tabas, Inflammation and plaque vulnerability, J. Intern. Med. 278 (2015) 483-493.

[13] P. Libby, P.M. Ridker, G.K. Hansson, Progress and challenges in translating the biology of atherosclerosis, Nature 473 (2011) 317-325.

[14] S. Fu, M.J. Davies, R. Stocker, R.T. Dean, Evidence for roles of radicals in protein oxidation in advanced human atherosclerotic plaque, Biochem. J. 333 (1998) $519-525$.

[15] S.L. Hazen, J.W. Heinecke, 3-chlorotyrosine, a specific marker of myeloperoxidasecatalysed oxidation, is markedly elevated in low density lipoprotein isolated from human atherosclerotic intima, J. Clin. Investig. 99 (1997) 2075-2081.

[16] L.J. Hazell, L. Arnold, D. Flowers, G. Waeg, E. Malle, R. Stocker, Presence of hypochlorite-modified proteins in human atherosclerotic lesions, J. Clin. Investig. 97 (1996) 1535-1544.

[17] A.A. Woods, S.M. Linton, M.J. Davies, Detection of hocl-mediated protein oxidation products in the extracellular matrix of human atherosclerotic plaques, Biochem. J. 370 (2003) 729-735.

[18] M.J. Davies, C.L. Hawkins, D.I. Pattison, M.D. Rees, Mammalian heme peroxidases: from molecular mechanisms to health implications, Antioxid. Redox Signal. 10 (2008) 1199-1234.

[19] B.S. van der Veen, M.P. de Winther, P. Heeringa, Myeloperoxidase: molecular mechanisms of action and their relevance to human health and disease, Antioxid. Redox Signal. 11 (2009) 2899-2937.

[20] S.J. Nicholls, S.L. Hazen, Myeloperoxidase and cardiovascular disease, Arterioscler. Thromb. Vasc. Biol. 25 (2005) 1102-1111.

[21] S.J. Klebanoff, Myeloperoxidase: friend and foe, J. Leukoc. Biol. 77 (2005) $598-625$

[22] S.J. Klebanoff, A.J. Kettle, H. Rosen, C.C. Winterbourn, W.M. Nauseef, Myeloperoxidase: a front-line defender against phagocytosed microorganisms, J. Leukoc. Biol. 93 (2013) 185-198.

[23] D.I. Pattison, M.J. Davies, Absolute rate constants for the reaction of hypochlorous acid with protein side chains and peptide bonds, Chem. Res. Toxicol. 14 (2001) 1453-1464.

[24] D.I. Pattison, M.J. Davies, Reactions of myeloperoxidase-derived oxidants with biological substrates: gaining insight into human inflammatory diseases, Curr. Med. Chem. 13 (2006) 3271-3290.

[25] D.I. Pattison, M.J. Davies, C.L. Hawkins, Reactions and reactivity of myeloperoxidase-derived oxidants: differential biological effects of hypochlorous and hypothiocyanous acids, Free Radic. Res. 46 (2012) 975-995.

[26] A. Daugherty, J.L. Dunn, D.L. Rateri, J.W. Heinecke, Myeloperoxidase, a catalyst for lipoprotein oxidation, is expressed in human atherosclerotic lesions, J. Clin. Invest. 94 (1994) 437-444.

[27] N. Tang, Y. Wang, Q. Mei, Myeloperoxidase g-463a polymorphism and susceptibility to coronary artery disease: a meta-analysis, Gene 523 (2013) 152-157.

[28] W.H. Tang, Y. Wu, S.J. Nicholls, S.L. Hazen, Plasma myeloperoxidase predicts incident cardiovascular risks in stable patients undergoing medical management for coronary artery disease, Clin. Chem. 57 (2011) 33-39.

[29] W.H.W. Tang, M.L. Brennan, K. Philip, W. Tong, S. Mann, F. Van Lente, S.L. Hazen, Plasma myeloperoxidase levels in patients with chronic heart failure, Am. J. Cardiol. 98 (2006) 796-799.

[30] S.J. Nicholls, W.H. Wilson Tang, D. Brennan, M.L. Brennan, S. Mann, S.E. Nissen, S.L. Hazen, Risk prediction with serial myeloperoxidase monitoring in patients with acute chest pain, Clin. Chem. 57 (2011) 1762-1770.

[31] J.P. Henderson, J. Byun, J. Takeshita, J.W. Heinecke, Phagocytes produce 5chlorouracil and 5-bromouracil, two mutagenic products of myeloperoxidase, in human inflammatory tissue, J. Biol. Chem. 278 (2003) 23522-23528.

[32] J. Takeshita, J. Byun, T.Q. Nhan, D.K. Pritchard, S. Pennathur, S.M. Schwartz, A. Chait, J.W. Heinecke, Myeloperoxidase generates 5-chlorouracil in human atherosclerotics tissue: a potential pathway for somatic mutagenesis by macrophages, J. Biol. Chem. 281 (2005) 3096-3104.

[33] S.L. Hazen, J.P. Gaut, J.R. Crowley, F.F. Hsu, J.W. Heinecke, Elevated levels of protein-bound p-hydroxyphenylacetaldehyde, an amino- acid-derived aldehyde generated by myeloperoxidase, are present in human fatty streaks, intermediate lesions and advanced atherosclerotic lesions, Biochem. J. 352 (2000) 693-699.

[34] A.K. Thukkani, J. McHowat, F.F. Hsu, M.L. Brennan, S.L. Hazen, D.A. Ford, Identification of alpha-chloro fatty aldehydes and unsaturated lysophosphatidylcholine molecular species in human atherosclerotic lesions, Circulation 108 (2003) 3128-3133.

[35] E. Malle, G. Waeg, R. Schreiber, E.F. Grone, W. Sattler, H.J. Grone, Immunohistochemical evidence for the myeloperoxidase $/ \mathrm{H}_{2} \mathrm{O}_{2}$ /halide system in human atherosclerotic lesions: colocalization of myeloperoxidase and hypochloritemodified proteins, Eur. J. Biochem. 267 (2000) 4495-4503.

[36] L.J. Hazell, G. Baernthaler, R. Stocker, Correlation between intima-to-media ratio, apolipoprotein B-100, myeloperoxidase, and hypochlorite-oxidized proteins in human atherosclerosis, Free Radic. Biol. Med. 31 (2001) 1254-1262.

[37] L.W. Castellani, J.J. Chang, X. Wang, A.J. Lusis, W.F. Reynolds, Transgenic mice express human mpo $-463 \mathrm{G} / \mathrm{A}$ alleles at atherosclerotic lesions, developing hyperlipidemia and obesity in -463G males, J. Lipid Res. 47 (2006) 1366-1377.

[38] R. Zhang, M.L. Brennan, X. Fu, R.J. Aviles, G.L. Pearce, M.S. Penn, E.J. Topol, D.L. Sprecher, S.L. Hazen, Association between myeloperoxidase levels and risk of coronary artery disease, JAMA 286 (2001) 2136-2142.

[39] H. Colognato, P.D. Yurchenco, Form and function: the laminin family of heterotrimers, Dev. Dynam. 218 (2000) 213-234.

[40] E. Hohenester, P.D. Yurchenco, Laminins in basement membrane assembly, Cell Adh. Migr. 7 (2013) 56-63.

[41] M.J. Davies, A.C. Thomas, Plaque fissuring - the cause of acute myocardial infarction, sudden ischaemic death and crescendo angina, Br. Heart J. 53 (1985) $363-373$.

[42] M.D. Rees, J.M. Whitelock, E. Malle, C.Y. Chuang, R.V. Iozzo, A. Nilasaroya, M.J. Davies, Myeloperoxidase-derived oxidants selectively disrupt the protein core of the heparan sulfate proteoglycan perlecan, Matrix Biol. 29 (2010) 63-73.

[43] J.P. Eiserich, S. Baldus, M.L. Brennan, W. Ma, C. Zhang, A. Tousson, L. Castro, A.J. Lusis, W.M. Nauseef, C.R. White, B.A. Freeman, Myeloperoxidase, a leukocytederived vascular no oxidase, Science 296 (2002) 2391-2394.

[44] A.A. Woods, M.J. Davies, Fragmentation of extracellular matrix by hypochlorous acid, Biochem. J. 376 (2003) 219-227.

[45] M.C. Vissers, C.C. Winterbourn, The effect of oxidants on neutrophil-mediated degradation of glomerular basement membrane collagen, Biochim. Biophys. Acta 889 (1986) 277-286.

[46] M.C.M. Vissers, C. Thomas, Hypochlorous acid disrupts the adhesive properties of subendothelial matrix, Free Radic. Biol. Med. 23 (1997) 401-411.

[47] M.C.M. Vissers, C.C. Winterbourn, Oxidative damage to fibronectin. 1. The effects of the neutrophil myeloperoxidase system and HOCl, Arch. Biochem. Biophys. 285 (1991) 53-59.

[48] T. Nybo, H. Cai, C.Y. Chuang, L.F. Gamon, A. Rogowska-Wrzesinska, M.J. Davies, Chlorination and oxidation of human plasma fibronectin by myeloperoxidase-derived oxidants, and its consequences for smooth muscle cell function, Redox Biol. 19 (2018) 388-400.

[49] E. Malle, L. Hazell, R. Stocker, W. Sattler, H. Esterbauer, G. Waeg, Immunologic detection and measurement of hypochlorite-modified ldl with specific monoclonal antibodies, Arter. Thromb. Vasc. Biol. 15 (1995) 982-989.

[50] J.C. Morris, The acid ionization constant of hocl from 5oc to 35oc, J. Phys. Chem. 70 (1966) 3798-3805.

[51] A.J. Kettle, C.C. Winterbourn, Assays for the chlorination activity of myeloperoxidase, Methods Enzymol. 233 (1994) 502-512.

[52] T. Masuda, M. Tomita, Y. Ishihama, Phase transfer surfactant-aided trypsin digestion for membrane proteome analysis, J. Proteome Res. 7 (2008) 731-740. 
[53] R.E. Ferguson, H.P. Carroll, A. Harris, E.R. Maher, P.J. Selby, R.E. Banks, Housekeeping proteins: a preliminary study illustrating some limitations as useful references in protein expression studies, Proteomics 5 (2005) 566-571.

[54] K. Tveen-Jensen, A. Reis, L. Mouls, A.R. Pitt, C.M. Spickett, Reporter ion-based mass spectrometry approaches for the detection of non-enzymatic protein modifications in biological samples, J. Proteom. 92 (2013) 71-79.

[55] J. Talib, D.I. Pattison, J.A. Harmer, D.S. Celermajer, M.J. Davies, High plasma thiocyanate levels modulate protein damage induced by myeloperoxidase and perturb measurement of 3-chlorotyrosine, Free Radic. Biol. Med. 53 (2012) 20-29.

[56] C.L. Hawkins, P.E. Morgan, M.J. Davies, Quantification of protein modification by oxidants, Free Radic. Biol. Med. 46 (2009) 965-988.

[57] H.C. Stary, A.B. Chandler, R.E. Dinsmore, V. Fuster, S. Glagov, W. Insull, M.E. Rosenfeld, C.J. Schwartz, W.D. Wagner, R.W. Wissler, A definition of advanced types of atherosclerotic lesions and a histological classification of atherosclerosis, Arterioscler. Thromb. Vasc. Biol. 15 (1995) 1512-1531.

[58] G. Marsche, A. Hammer, O. Oskolkova, K.F. Kozarsky, W. Sattler, E. Malle, Hypochlorite-modified high density lipoprotein, a high affinity ligand to scavenger receptor class b, type i, impairs high density lipoprotein-dependent selective lipid uptake and reverse cholesterol transport, J. Biol. Chem. 277 (2002) 32172-32179.

[59] A. Hammer, G. Desoye, G. Dohr, W. Sattler, E. Malle, Myeloperoxidase-dependent generation of hypochlorite-modified proteins in human placental tissues during normal pregnancy, Lab. Investig. 81 (2001) 543-554.

[60] H.J. Chen, Y.F. Yang, P.Y. Lai, P.F. Chen, Analysis of chlorination, nitration, and nitrosylation of tyrosine and oxidation of methionine and cysteine in hemoglobin from type 2 diabetes mellitus patients by nanoflow liquid chromatography tandem mass spectrometry, Anal. Chem. 88 (2016) 9276-9284.

[61] S. Baldus, J.P. Eiserich, A. Mani, L. Castro, M. Figueroa, P. Chumley, W. Ma, A. Tousson, T.C.R. White, D.C. Bullard, M.-L. Brennan, A.J. Lusis, K.P. Moore, B.A. Freeman, Endothelial transcytosis of myeloperoxidase confers specificity to vascular ecm proteins as targets of tyrosine nitration, J. Clin. Investig. 108 (2001) 1759-1770.

[62] M.D. Rees, L. Dang, T. Thai, D.M. Owen, E. Malle, S.R. Thomas, Targeted subendothelial matrix oxidation by myeloperoxidase triggers myosin II-dependent deadhesion and alters signaling in endothelial cells, J. Leukoc. Biol. 53 (2012) 2344-2356.

[63] C.I. Murray, J.E. Van Eyk, A twist on quantification: measuring the site occupancy of S-nitrosylation, Circ. Res. 111 (2012) 1253-1255.

[64] G.E. Reid, K.D. Roberts, E.A. Kapp, R.J. Simpson, Statistical and mechanistic approaches to understanding the gas-phase fragmentation behavior of methionine sulfoxide containing peptides, J. Proteome Res. 3 (2004) 751-759.

[65] S. Barata-Vallejo, C. Ferreri, T. Zhang, H. Permentier, R. Bischoff, K. Bobrowski, C. Chatgilialoglu, Radiation chemical studies of gly-met-gly in aqueous solution, Free Radic. Res. 50 (2016) S24-S39.

[66] D.I. Pattison, C.L. Hawkins, M.J. Davies, What are the plasma targets of the oxidant hypochlorous acid? A kinetic modeling approach, Chem. Res. Toxicol. 22 (2009) 807-817.

[67] H.J. Grone, E.F. Grone, E. Malle, Immunohistochemical detection of hypochloritemodified proteins in glomeruli of human membranous glomerulonephritis, Lab. Investig. 82 (2002) 5-14.

[68] B. Shao, S. Pennathur, J.W. Heinecke, Myeloperoxidase targets apolipoprotein A-I, the major high density lipoprotein protein, for site-specific oxidation in human atherosclerotic lesions, J. Biol. Chem. 287 (2012) 6375-6386.

[69] L. Zheng, B. Nukuna, M.L. Brennan, M. Sun, M. Goormastic, M. Settle, D. Schmitt, X. Fu, L. Thomson, P.L. Fox, H. Ischiropoulos, J.D. Smith, M. Kinter, S.L. Hazen, Apolipoprotein A-I is a selective target for myeloperoxidase-catalyzed oxidation and functional impairment in subjects with cardiovascular disease, J. Clin. Investig. 114 (2004) 529-541.

[70] S. Baldus, C. Heeschen, T. Meinertz, A.M. Zeiher, J.P. Eiserich, T. Munzel, M.L. Simoons, C.W. Hamm, Myeloperoxidase serum levels predict risk in patients with acute coronary syndromes, Circulation 108 (2003) 1440-1445.

[71] S. Baldus, J.P. Eiserich, M.L. Brennan, R.M. Jackson, C.B. Alexander, B.A. Freeman, Spatial mapping of pulmonary and vascular nitrotyrosine reveals the pivotal role of myeloperoxidase as a catalyst for tyrosine nitration in inflammatory diseases, Free Radic. Biol. Med. 33 (2002) 1010-1019.

[72] E.C. Kennett, C.Y. Chuang, G. Degendorfer, J.M. Whitelock, M.J. Davies, Mechanisms and consequences of oxidative damage to extracellular matrix, Biochem. Soc. Trans. 39 (2011) 1279-1287.

[73] M. Segelmark, B. Persson, T. Hellmark, J. Wieslander, Binding and inhibition of myeloperoxidase (MPO): a major function of ceruloplasmin? Clin. Exp. Immunol. 108 (1997) $167-174$

[74] A.V. Sokolov, K.V. Ageeva, O.S. Cherkalina, M.O. Pulina, E.T. Zakharova, V.N. Prozorovskii, D.V. Aksenov, V.B. Vasilyev, O.M. Panasenko, Identification and properties of complexes formed by myeloperoxidase with lipoproteins and ceruloplasmin, Chem. Phys. Lipids 163 (2010) 347-355.

[75] C. Storkey, M.J. Davies, D.I. Pattison, Reevaluation of the rate constants for the reaction of hypochlorous acid $(\mathrm{HOCl})$ with cysteine, methionine, and peptide derivatives using a new competition kinetic approach, Free Radic. Biol. Med. 73 (2014) 60-66.

[76] M. Karimi, M.T. Ignasiak, B. Chan, A.K. Croft, L. Radom, C.H. Schiesser, D.I. Pattison, M.J. Davies, Reactivity of disulfide bonds is markedly affected by structure and environment: implications for protein modification and stability, Sci. Rep. 6 (2016) 38572.

[77] C.L. Hawkins, M.J. Davies, Hypochlorite-induced damage to proteins: formation of nitrogen-centred radicals from lysine residues and their role in protein fragmentation, Biochem. J. 332 (1998) 617-625.

[78] C.L. Hawkins, M.J. Davies, Hypochlorite-induced oxidation of plasma proteins: formation of nitrogen-centred radicals and their role in protein fragmentation, Curr. Top. Biophys. 22 (Suppl. B) (1998) 89-98.

[79] C.L. Hawkins, D.I. Pattison, M.J. Davies, Hypochlorite-induced oxidation of amino acids, peptides and proteins, Amino Acids 25 (2003) 259-274.

[80] L.J. Hazell, R. Stocker, Oxidation of low-density lipoprotein with hypochlorite causes transformation of the lipoprotein into a high-uptake form for macrophages, Biochem. J. 290 (1993) 165-172.

[81] G.J. Handelman, Z.D. Nightingale, G.G. Dolnikowski, J.B. Blumberg, Formation of carbonyls during attack on insulin by submolar amounts of hypochlorite, Anal. Biochem. 258 (1998) 339-348.

[82] H. Lin, B.S. Levison, J.A. Buffa, Y. Huang, X. Fu, Z. Wang, V. Gogonea, J.A. DiDonato, S.L. Hazen, Myeloperoxidase-mediated protein lysine oxidation generates 2-aminoadipic acid and lysine nitrile in vivo, Free Radic. Biol. Med. 104 (2017) 20-31.

[83] D. Pulido, S.A. Hussain, E. Hohenester, Crystal structure of the heterotrimeric integrin-binding region of laminin-111, Structure 25 (2017) 530-535.

[84] D.G.K. Rasmussen, M.A. Karsdal, Laminins. biochemistry of Collagens, Laminins Elastin: Struct. Funct. Biomark. (2016) 163-196.

[85] M. Yamada, K. Sekiguchi, Molecular basis of laminin-integrin interactions, Curr. Top. Membr. 76 (2015) 197-229.

[86] F. Carafoli, S.A. Hussain, E. Hohenester, Crystal structures of the network-forming short-arm tips of the laminin beta1 and gamma1 chains, PLoS One 7 (2012) e42473.

[87] P.D. Yurchenco, E.C. Tsilibary, A.S. Charonis, H. Furthmayr, Laminin polymerization in vitro. Evidence for a two-step assembly with domain specificity, J. Biol. Chem. 260 (1985) 7636-7644.

[88] E. Appella, I.T. Weber, F. Blasi, Structure and function of epidermal growth factorlike regions in proteins, FEBS Lett. 231 (1988) 1-4.

[89] C.G. Davis, The many faces of epidermal growth factor repeats, New Biol. 2 (1990) $410-419$.

[90] U. Mayer, R. Nischt, E. Poschl, K. Mann, K. Fukuda, M. Gerl, Y. Yamada, R. Timpl, A single EGF-like motif of laminin is responsible for high affinity nidogen binding, EMBO J. 12 (1993) 1879-1885. 